\title{
ASPECTOS POLEMICOS DE LAS CONTRIBUCIONES ESPECIALES POR OBRAS
}

\author{
352.336 .8
}

por

\section{J. M. Casal López-Valeiras}

Doctor Ingeniero Industrial

SUMARIO: I. ASPECTOS BASICOS: 1. PRINCIPIOS TRIBUTARIOS. 2. Difícil eVAluación DE LOS BENEFICIOS ESPECIALES. 3. La NORMaTIVA ACTUAL POTENCIA LA IMPOSICIÓN. 4. El LEGISLADOR MARGINA ASPECTOS DOCTRINALES.-II. CONSECUENCIAS DE LA NORMATIVA: 1. El BENEFICIO ESPECIAL: UNA ENTELEQUIA. 2. MINIMIZA LAS VENTAJAS DEL TRIBUTO. 3. PaRAdóJICA INCIDENCIA FINANCIERA. III. ASPECTOS SECTORIALES: 1. INVALIDEZ DE LA GENERALIZACIÓN IMPOSITIVA. 2. IRREAL CUANTIFICACIÓN DE LOS BENEFICIOS. 3. OTROS ASPECTOS DISCUTIBLES.-IV. COMENTARIOS FINALES.

\section{ASPECTOS BASICOS}

1. Principios tributarios

Después de entregado este artículo a la REVISTA, el legislador ha modificado de nuevo la normativa de imposición de las contribuciones especiales (Real Decreto-ley 3/1981), volviendo a planteamientos cercanos a los del texto articulado y refundido de las Leyes de Bases de Régimen local que, para el autor, eran más satisfactorios que los de la legislación posterior. Dada la nueva norma, el artículo cobra un mayor sentido práctico, pues lo que en él se planteó en un plano meramente 
crítico, puede proporcionar ahora pautas para la exacción del tributo, dado que el Real Decreto-ley 3/1981 concede a las Corporaciones locales una gran discrecionalidad en su imposición.

Cuando un ente público realiza una obra que condiciona las funciones de utilidad o producción de otros agentes, pero no a través del mercado, crea externalidades que afectan a la comunidad, las cuales-como ocurre la mayoría de las veces-es posible incidan de forma especial sobre determinados intereses privados. Es, por tanto, equitativo que estos últimos contribuyan a la financiación del gasto público realizado en proporción similar a las ventajas individuales que obtengan, que serán así objeto de la debida contraprestación, pues, como ya se indicaba en el proyecto de exacciones municipales de CANALEJAS-primer intento legal para establecer contribuciones especiales-, el exigir impuestos "para costear totalmente obras y servicios que aun siendo de interés público, benefician especialmente a personas o clases determinadas, constituye un despojo legal de los contribuyentes en favor de intereses particulares, por todo el importe en que éstos son especialmente beneficiados».

Consecuentemente con este planteamiento, por el Real Decreto de 31 de diciembre de 1917, se creó el primer cuerpo legal (1) por el que se autorizó el establecimiento y exacción de contribuciones especiales-a fin de evitar que se impusieran «gravámenes para favorecer con sus ingresos intereses particulares»-, definidas en la Ley General Tributaria (art. 26, b) ) como «tributos cuyo hecho imponible consiste en la obtención por el sujeto pasivo de un beneficio o de un aumento de valor de sus bienes (2), como consecuencia de la realización de obras públicas o del establecimiento o aplicación de servicios públicos».

Como indicó AlbiÑana en el prólogo del libro Las contribucio-

(1) En fechas anteriores se impusieron gravámenes cuyas bases coincidian, en cierta medida, con las de las actuales contribuciones especiales. Por ejemplo, se puede recordar que desde FELIPE II se intentó repetidamente que los vecinos de Madrid encendiesen y conservasen, incluso en algunos casos instalasen, los faroles de alumbrado público, pero el incumplimiento de esta obligación permite considerar a CARLos III el auténtico creador de este servicio. Pues bien, por la Real Orden de 25 de septiembre de 1765 se impuso la obligación, a los propietarios de las casas, de pagar el consumo de cada farol «en buena moneda».

(2) Esta bipartición del tributo, basada en la diferencia de dos hechos imponibles, figura en el Real Decreto de 31 de diciembre de 1917 y sucesivas disposiciones hasta que la Ley del Suelo de 1956 las unifica (art. 183), criterio que es adoptado desde entonces por el legislador, excepto en la Ley del Municipio de Barcelona (art. 65) y su Reglamento de Hacienda (art. 10). 
nes especiales en España (3), este tributo «cumple análoga función económica que el coste de una mejora por cuenta propia» $\mathrm{y}$, en cierta medida, permite recuperar para la comunidad las ventajas individualizadas que ocasiona la Administración pública. Así, las contribuciones especiales se rigen más por el principio de beneficio sin causa que por el de capacidad económica, pues para que sea procedente su imposición es requisito imprescindible la existencia de un beneficio especial que exteriorice la capacidad contributiva (4) del sujeto pasivo, en base a la cual se le exige contribuya directamente a satisfacer parte del costo ocasionado por la actividad del ente público.

GONZÁLEZ-BERENGUER-un duro crítico de estos tributos por considerarlos «inaplicables (o muy difícilmente aplicables)» (5)indicó que «nadie ignora que las contribuciones especiales fueron un fabuloso paso adelante dado en el camino del acercamiento del sistema hacendístico local a los postulados de la justicia distributiva», y afirmó: "el pago de servicios u obras por los directamente beneficiados es una gran aportación al altar de la Justicia". A esta indudable realidad en el plano conceptual, se une que este tributo puede contribuir muy positivamente a la mejora de la hacienda municipal-sobre todo en coyunturas como la actual, pues sus otros recursos son más rígidos a la inflación que los costos de las obras y servicios-y, previsiblemente, «aumenta la eficacia asignatoria del sector público» (6), como consecuencia de la afectación de los ingresos a actuaciones específicas, aunque, incluso sin salirse de dicho plano, tiene serios inconvenientes: en muchos casos es regresivo (7), su imposición puede efectuarse en momentos inoportunos

(3) Vega Herrero, M.: Las contribuciones especiales en España, Madrid, Instituto de Estudios Fiscales, 1975, pág. 17.

(4) Constituyen una excepción las obras provocadas por personas o clases determinadas, de acuerdo con lo dispuesto en la Ley de Régimen local, Ley del Suelo, Leyes de los Municipios de Madrid y Barcelona, etc., aunque este supuesto no es considerado en la Ley General Tributaria ni en el Real Decreto 3250/1976, que con «criterio plausible solamente considera(n) como aspecto material del elemento objetivo del hecho imponible la obtención de un beneficio especial» (Vega Herrero, M.: Ob. cit., pág. 101).

(5) GONZÁLEZ-BERENGUER, J. L.: Gestión financiera y control del urbanismo, Madrid, Instituto de Estudios de Administración Local, 1979, págs. 675 y 678.

(6) Buchanan, J. M., y otros: El sector público en las economías de mercado, Madrid, Espasa-Calpe, S. A., 1979, pág. 135.

(7) Aún en el plano teórico los gravámenes basados en el principio de beneficio resultan más regresivos que los fundamentados en la capacidad de pago, pues su exacción es menos gravosa, para los más capaces económicamente, que los tributos directos progresivos. Por su parte, en la realidad nacional, la imposición de contribuciones especiales obligatorias - en base a la tipología de la actuación pública-con porcentajes de participación en el costo de las obras de carácter general, fijos y con una gran parte de los módulos de reparto inadecuados-el más utilizado, los metros lineales de 
para el contribuyente (8), su costo de recaudación es posible que sea alto-y complejo-si se aplica con equidad, etc.

\section{Difícil EVALUACión DE los BENEFicios ESPECIALES}

El indudable atractivo y validez conceptual de las contribuciones especiales exige, para su correcta aplicación, localizar, en primer lugar, los agentes que se benefician especialmente de la específica actuación del ente público, cuyo coste se financia parcialmente con este tributo; en segundo término, deben determinarse los beneficios especiales que obtienen, $\mathrm{y}$, por último, es necesario establecer las cuotas individuales que armonicen la carga fiscal con las ventajas obtenidas. Es evidente que la aceptable consecución de estos tres objetivos es condición necesaria para alcanzar una equitativa distribución del gravamen, la cual, según se establece en el artículo 3: de la Ley General Tributaria, constituye una de las bases de la ordenación de los tributos. Complementariamente-y hasta donde sea posible-deben establecerse procedimientos de aplicación eficaces, simples y económicos que aseguren la satisfacción del principio de certeza y proporcionen adecuadas garantías jurídicas al contribuyente.

Para determinar tanto los sujetos pasivos del tributo como la proporción con que deben contribuir a la financiación de los gastos ocasionados por una actuación del ente local-el campo de acción. de las contribuciones especiales se limita en España a las haciendas locales y provinciales (9)_es necesario analizar las características de las externalidades que aquélla crea, es decir, si se orientan principalmente hacia las personas o a la propiedad-en este caso es necesario definir hasta qué punto los beneficios ocasionados afectan especialmente a sus dueños, usuarios o a ambos-y evaluar las ventajas especiales que obtiene cada agente, todo ello logrado con una precisión aceptable desde el punto de vista de la equidad. Ciertamente no parece fácil alcanzar estos objetivos con la precisión.

fachada, casi siempre lo es-tienen en muchos casos un indudable carácter regresivo, independientemente de que, con dificultad, su aplicación se ajuste al principio de beneficio, como se indica más adelante.

(8) Hicks indicó (Forstall, R., y otros: Problemas de las Areas Metropolitanas, Madrid, Instituto de Estudios de Administración Local, 4. ${ }^{2}$ ed., 1976, pág. 173) la certidumbre, referida a la ley tributaria, reviste gran importancia para los contribuyentes, especialmente para el mundo de los negocios, respecto del cual una recaudación inesperada $o$ incluso el simple temor de que sobrevenga puede dañar seriamente los planes: empresariales.

(9) El presente artículo se limita a las obras municipales. 
requerida por los principios de la justicia distributiva (10), pues si estimar los beneficios especiales directos constituye un serio problema, ya que muchos de ellos son intangibles y de compleja evaluación, la cuantificación de los indirectos, cada vez más importantes dadas las crecientes interrelaciones socio-económicas de la actividad urbana, presenta dificultades que no pueden ser resueltas en muchos casos con aceptable fiabilidad dado el estado de los conocimientos, a pesar de los indudables avances logrados últimamente.

Por otro lado, la enorme complejidad de la vida ciudadana hace muy difícil desagregar, de forma explícita, la incidencia de una obra sobre las funciones de utilidad o de producción, pues ambas se ven condicionadas por tal cúmulo de circunstancias socio-económicas y técnicas, que incluso pueden ocasionar, en casos límites, externalidades negativas para muchos agentes, en vez de los previstos efectos externos positivos. Por ejemplo, una mejora en el firme de una calzada puede generar un tráfico inducido que influya muy desfavorablemente sobre las condiciones ambientales de la calle: polución, ruido, congestión, etc., ocasionando así unos costos sociales que pueden superar para algunos los beneficios que reporta la accesibilidad lograda. De esta forma, los condicionantes ocasionados por las decisiones y comportamientos de otros determinan la incidencia de la externalidad, incluso pueden afectar a su signo, y son así los determinantes de la evolución de la urbe-y, por tanto, de las economías externas que ofrece en cada zona-, pues, como indicó (11) Hicks, "en términos generales, no es muy grande la relación que con ello tengan las actividades específicas del Gobierno en la ciudad", aunque, indudablemente, la condicionan mediante su actuación tangible e intangible.

A todo esto se une, además, que muchos beneficios que proporcionan las externalidades creadas no tienen precios de mercado que orienten sobre su valoración-cuando son intermedios es posible cuantificarlos algunas veces por el valor del producto del esca-

(10) Aunque es una opinión generalizada que existen enormes dificultades para determinar las ventajas que ocasiona una específica actuación de la Corporación local no es compartida por todos. Así la Comisión de Urbanismo y Servicios Comunes de Barcelona y otros Municipios indicó que la construcción y mantenimiento de vías de comunicación, alumbrado público, etc., "son servicios cuyos usuarios son fácilmente localizables y en los cuales los beneficios que de ellos se obtienen son medibles de una forma relativamente fácil» (Estudio sobre recursos economicos para la actuación urbanística y la prestación de servicios en la comarca de Barcelona. Edita Comisión de Urbanismo y Servicios Comunes de Barcelona y otros Municipios, tomo II, Barceıona, 1973, pág. 370).

(11) Forstall, R., y otros: Ob. cit., pág. 176. 
lón siguiente-, mientras, en otros casos, la actuación municipal ocasiona, simultáneamente, efectos externos que, por no satisfacer el óptimo de PARETo, llegan a tener hasta signos distintos para las diversas funciones de utilidad o producción a las que afectan, ya que, en muchas ocasiones, éstas tienen exigencias conflictivas (12). Por ello (13), «la única solución posible (...) es derivar alguna valoración implícita que refleje lo que la sociedad»—en la aplicación de las contribuciones especiales, los miembros que se benefician

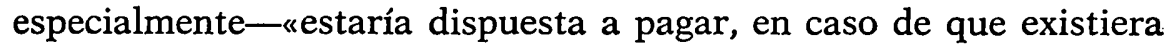
un mercado de efectos externos positivos», o "admitir, como compensación para aceptar la externalidad negativa» (14), aunque, como. resalta HrRs H (15), «más que indicar la demanda efectiva, este método ayuda a indicar cuál debiera ser» si los afectados actuasen con total racionalidad.

Para concluir este esbozo de las dificultades existentes para conocer quiénes se benefician de una actuación de las Administraciones municipales y determinar las ventajas potenciales que obtiene cada uno, es interesante indicar que los costes concurridos para realizar los correspondientes análisis pueden llegar a superar cuantitativamente el importe de las contribuciones especiales que se aplicarán; de ahí que sólo estarán justificadas cuando los resultados netos que se logren con su imposición alcancen un aceptable nivel positivo. Por otro lado, es indudable que la inmensa mayoría de las Corporaciones locales no disponen ni de los recursos humanos (16):

(12) A lo largo del verano de 1980 se planté una fuerte polémica, a nivel nacional, en torno a la realización de una vía pública para interconectar los tráficos que confluyen a Soria. Esta polémica se centró en dos opciones, una de menor coste-los datos proporcionados a la opinión pública sobre este aspecto fueron contradictorios e insuficientes-y otra que afectaba negativamente a la estética de un paraje como consecuencia de la realización de un puente. La diversa valoración de la incidencia de ambas opciones por los distintos agentes constituye un claro ejemplo de lo difícil que resulta que no surjan exigencias conflictivas ante la realización de una obra.

(13) AlBI IBÁÑEZ, E., y otros: Introducción a la economía del coste-beneficio, Madrid, Instituto de Estudios Fiscales, 1976, pág. 40.

(14) Dado que la contribución especial se devenga como consecuencia de una actividad de la Corporación local que proporciona una ventaja especial individualizada, sensu contrario, si ésta ocasiona un perjuicio a determinados agentes, parece logico que diese lugar a una imposición negativa para enjugar los perjuicios causados, pues, como indica Vega (Vega Herrero, M.: Ob. cit., pág. 69), "de esta forma se conseguiría un reparto equitativo de los beneficios y de las cargas».

(15) Hirsh, W. Z.: Análisis de economía urbana, Madrid, Instituto de Estudios de Administración Local, 1977, pág. 425.

(16) Aun cuando la partida del personal activo supuso, en 1975, el 42,12 por 100 del importe total de gastos incluidos en presupuestos ordinarios de los Ayuntamientos de régimen común-diez años antes representaba el 43,52 por 100-, el número de arquitectos, ingenieros, peritos, aparejadores y ayudantes de sus plantillas eran los incluidos en el cuadro siguiente: 
ni de los medios operativos necesarios para realizar este tipo de análisis, que aún tiene hoy limitaciones muy serias dada la escasa capacidad existente para valorar una gran parte de los bienes sociales, pero que, como indicó Williams - citado por AlBI (17)-, no pueden servir como excusa "para no abandonar las viejas prácticas, que tienen aún más defectos».

\section{La NORMATIVA ACTUAL POTENCIA LA IMPOSICIÓN}

Hace ya más de cien años, WAGNER formuló, por primera vez, su famosa ley sobre el incremento regular del gasto público, que ALVAREZ RENDUELES matizó al indicar (18) que "quiso referirse al aumento de participación relativa del sector público en $\mathrm{PNB}$ », en base a observaciones empíricas, cronológicas y espaciales que demostraban la creciente actividad del sector público. Así, a pesar de que hoy se va extendiendo en los países industrializados de Occidente la opinión de que el gasto público no debe sobrepasar el excedente del mercado, la tasa anual de su crecimiento en relación al PIB ha sido el 2 por 100 durante los años sesenta en los países de la CEE, y en España, del 5 por 100, aun cuando en nuestro país alcanza proporciones del PIB unos 15 puntos menos que en las Naciones de la Comunidad. Pues bien, un incremento de los gastos de los Ayuntamientos muy superior al de sus recursos ocasionó una crisis endémica en las haciendas municipales, que llegó a uno de sus momentos más críticos a principio de siglo y motivó la instauración de las contribuciones especiales como un recurso idóneo para su potenciación financiera, cuando se producen beneficios particulares diferenciados por la actuación del ente local.

\begin{tabular}{|c|c|c|c|c|c|}
\hline Habitantes por Municipio & $>5.000$ & 5.001 a 20.000 & 20.001 a 100.00 & $<100.000$ \\
\hline Número de Municipios ... ... ... & 6.977 & 828 & 196 & 48 \\
\hline Número de arquitectos, etc. ... & 31 & 204 & 415 & 1.050 \\
\hline
\end{tabular}

Fuentes: Anuario Estadistico de las Corporaciones Locales y Sección de Mecanización del Servicio Nacional de Asesoramiento e Inspección de las Corporaciones Locales.

(17) ALBI IBÁÑ̃E, E.: «Nota sobre la validez metodológica del análisis costobeneficio», Hacienda Pública Española, núm. 40, 1976, pág. 200.

(18) Alvarez Rendueles, J. R., y otros: La dinámica del gasto público, Madrid, Instituto de Estudios Fiscales, 1974, pág. 13. 
La necesidad de mejorar la financiación de los entes locales continúa teniendo plena vigencia en la actualidad, como recoge la exposición de motivos del Real Decreto-ley 11/1979, al indicar que su elaboración se realizó «a partir de la decidida voluntad política que comparten el Gobierno y las fuerzas políticas de más significativa representación en las Corporaciones y en el Parlamento de ir resolviendo la ya crónica situación estructuralmente deficitaria de las Corporaciones locales», objetivo que fue incluido en las propuestas que el Gabinete sometió a la confianza del Congreso en el pasado septiembre, al indicar que continuaría «el proceso de saneamiento y mejoras de las haciendas locales, mediante el progresivo incremento de sus dotaciones, el perfeccionamiento de su fiscalidad y una adecuada ordenación del crédito".

Este resultado hacendístico fue el que justificó, en parte, la instauración, por el Real Decreto de 31 de diciembre de 1917, de «un sistema amplio y eficaz de contribuciones especiales», pues, como se indicaba en la exposición de motivos, su carencia tenía «detenida la iniciativa de nuestros Ayuntamientos para un gran número de obras y servicios municipales». De forma similar, la regulación efectuada para la aplicación de contribuciones especiales por la Ley 48/1966 (19), antecedente inmediato del Real Decreto 3250/1976, hoy vigente, buscaba "alcanzar la obligatoriedad, efectividad y simplificación de su exacción, de modo que su producto alcance la importancia que realmente debe tener en las finanzas de los Municipios».

Este importante objetivo de las contribuciones especiales debe ser compatible, lógicamente, con la base doctrinal del tributo que considera el beneficio individualizado ocasionado por una actuación del ente local como su elemento angular e índice básico para medir determinada y específica manifestación de la capacidad contributiva-que se supone añadida a la general de los ciudadanosy, por tanto, constituye su razón de ser y fundamento jurídico.

A pesar de ello, se observa con perplejidad que la normativa de aplicación de las contribuciones especiales, a lo largo de la evolución legislativa, parece que va desdibujando estos principios conceptuales en aras del objetivo económico, hasta el punto de llegar

(19) Los expertos nunca se pusieron de acuerdo sobre si estuvieron o no en vigor las disposiciones de la Ley 48/1966-hoy derogada-relativas a las contribuciones especiales (art. 9), aunque la mayoría se inclinó por la tesis negativa al considerar que su aplicación exigía un desarrollo posterior mediante un texto articulado. No obstante, su normativa fue aplicada en numerosas ocasiones. 
a desnaturalizarlos al mostrar las normas una clara incoherencia con los fundamentos jurídicos.

Ello parece que es asumido paladinamente por los expertos (20). Dos testimonios de autoridad, y no son más que unos ejemplos de los muchos que se podrían citar, lo confirman. Llamas lo expresa así (21): "se entiende que el beneficio y su obtención opera como criterio material de justicia para la redacción de las normas de imposición del tributo, pero no tiene eficacia en el momento de la aplicación concreta del mismo", mientras que CoRTÉs indica (22) que: «es irrelevante que el contribuyente obtenga de hecho o no el beneficio». De esta forma, parece que con un criterio más posibilista -dada la dificultad existente para la determinación de los agentes privados que se benefician especialmente de una externalidad-que de ortodoxia tributaria, no se duda en soslayar los aspectos definitorios de la capacidad contributiva-«es razonable que el tributo no deje de imponerse por la imposibilidad de determinar el incremento de valor", indica VEGA (23)-, marginando la evaluación de las ventajas individualizadas y la búsqueda de una equitativa distribución de la carga, mientras se insiste sobre otros-por ejemplo, que no se permitan "enriquecimientos injustos del beneficiado especialmente en perjuicio del erario municipal» (24)-que, en este contexto, se basan normalmente en meras hipótesis intuitivas o anecdóticas que tienen muy poca relación con la realidad.

\section{EL LEGISLADOR MARGINA ASPECTOS DOCTRINALES}

En la legislación inicialmente promulgada sobre las contribuciones especiales se hizo una distinción entre las posibles ventajas individualizadas: aumento determinado del valor de ciertas fincas, y aunque no se produjese éste, cuando se beneficiase especialmente

(20) El autor desea que sus comentarios incluyan sus opiniones sin ninguna reserva. La indudable audacia que ello conlleva estima que es el único posible interés que puede tener este trabajo al facilitar al lector la visión del tema desde el punto de vista de un sector-de un miembro de él-que está involucrado en la aplicación de las contribuciones especiales, frecuentemente con un peso real muy superior al que debiera, pero que, de forma un tanto paradojica, pocas veces expresa su opinión.

(21) Llamas Labella, M. A.: Las contribuciones especiales, Bolonia, Pub. del Real Colegio de España en Bolonia, 1973, pág. 84.

(22) CoRTÉs, M.: Ordenamiento tributario español, 2." ed., Madrid, Ed. Tecnos, 1970 , pág. 255.

(23) Vega Herrero, M.: Ob. cit., pág. 152.

(24) Díaz Eimil, E.: "Tasas y contribuciones especiales», Revista de Economía y Hacienda Local, mayo-agosto 1976, núm. 17, pág. 99. 
a personas o clases específicas, creando con ello una dualidad más que discutible en el plano teórico, pues ambas responden a un solo concepto: el beneficio privatizado, pero que es posible justificar, en alguna medida, por razones operativas.

Así, se puede recordar que la Ley de Régimen local de 1955 limitaba su obligatoriedad (25) a las obras en que se produzca un incremento de valor (arts. 451 y 462) y establecía un admisible criterio para su aplicación en tal caso: que el importe de las contribuciones no exceda «ni el 90 por 100 del incremento de valor ni del coste total de las obras» (art. 467, 1).

Por otro lado, el legislador consideró en dicha Ley que algunos tipos de realizaciones municipales pueden ocasionar beneficios especiales-los especifica en el artículo 469-, pero al estimar que no se producirán siempre establece que la aplicación del gravamen en estos casos será potestativa del ente local (art. 451, 2), limitándose a fijar, de forma coactiva, los límites máximos de su cuantía (artículo 470,1 ) en base a la tipología de la actuación y su costo, aspectos éstos más discutibles, aunque válidos, ya que obras análogas ocasionarán muy diversas ventajas individualizadas que dependerán de condicionantes socio-económicos y urbanos, por lo que «el principio del beneficio no se puede llevar a la práctica directamente y con generalidad» (26), como indicó ALBI. Para adoptar la parte alícuota del costo de realización, que debe ser cubierta mediante contribuciones especiales, se atenderá-indica la Ley de Régimen local-«a la importancia relativa del interés público y de los intereses particulares que concurran en la obra o instalación de que se. trate» (art. 472, 2), y especifica que la fijación de los módulos individuales se hará «atendiendo a la justicia del reparto y a la clara determinación de las cuotas» (art. 471).

Las indicadas diferencias que la Ley de Régimen local establece para la aplicación del tributo, según se produzca un incremento de valor de ciertas fincas o un beneficio especial a personas o clases determinadas, parece que constituyen así motivaciones operativas

(25) En la Ley de Régimen local se preveía la imposición de contribuciones especiales (art. 451, b) cuando las obras «se provocaran de un modo especial por personas o clases individualizadas, aunque no existieran aumentos determinados de valor», criterio que fue mantenido en parte de la legislación posterior: Ley del Suelo en: 1956 (art. 138) y de 1976 (art. 198, 1), pero no en la Ley 48/1966 ni en el Real Decreto $3250 / 1976$. Es previsible que el legislador considerase que si la realización fuese provocada por particulares, éstos obtendrían un cierto beneficio especial, aunque no se demostrase, que justificaría la imposición del gravamen, criterio que parece bastante plausible, aunque ello pudiera ser más dudoso si se imponen no sólo a los promotores, sino a todos los afectados.

(26) Buchanan, J. M., y otros: Ob. cit., pág. 135. 
suficientes para su partición y, lo que tiene una importancia decisoria bajo el punto de vista de la doctrina, se adecúa en ambos casos a los postulados tributarios, aunque ello suponga limitar su operatividad (27) y aun conceder a los Municipios una discrecionalidad que, en ciertos casos-quizá en la mayoría-, sobrepasa, incluso hoy, sus posibilidades reales de asegurar una fiable evaluación de las ventajas particularizadas que una específica obra municipal ocasiona.

Pero en la normativa aprobada con posterioridad a la Ley de Régimen local, el legislador parece que no duda en subordinar los principios tributarios básicos de las contribuciones especiales al. reforzamiento de las haciendas locales, y en este contexto dicta de forma expeditiva la sistemática necesaria para alcanzar su objetivo prioritario: elimina las causas que, en mayor grado, podrían dificultar su aplicación, aunque ello suponga marginar la base doctrinal del hecho imponible y minimizar las garantías que inicialmente la Ley concedía al contribuyente. Así, por ejemplo, como uno de los problemas más difíciles de resolver en la práctica es fijar el importe del gravamen-por principios de equidad y generalidad debía establecerse en función de los beneficios especiales individualizados que ocasiona la obra-, lo objetiva como un porcentaje de su costo, creando así un índice meramente jurídico sin relación con las verdaderas ventajas que en cada ocasión se producirán, y para facilitar aún más la imposición del tributo, dicha evaluación la establece, en la mayoría de los casos, de forma unívoca, con carácter general y obligatorio, apartándose con ello de la realidad, mientras elimina coactivamente toda posibilidad de tener en cuenta la incidencia particularizada de cada realización concreta, pues hace incurrir

(27) Es innegable que la Ley de Régimen local tiene limitada operatividad práctica, pero no cabe duda que establece unas bases que debían estimular una mejora constante en la evaluación de las ventajas especiales que los Ayuntamientos ocasionan. Por el contrario, la normativa vigente para los Municipios de régimen común, desarrollada en el Real Decreto 3250/1976, no sólo no contribuirá a ello al establecer la obligatoriedad indiscriminada de su aplicación cuando se efectúen específicas realizaciones (art. 26, 1) y determinar, $a$ priori, las cuotas individuales (art. 29, 1), sino que incluso frenará, mientras esté vigente, su posible intento por innecesario, a pesar de que cada vez son mayores las posibilidades de satisfacer exigencias de equidad, dado el incremento de los conocimientos. y el carácter repetitivo de la actuación municipal. Un ejemplo parcial de ello lo proporciona la Ordenanza Fiscal número 20 del Ayuntamiento de Barcelona, pues al especificar la aplicación de contribuciones especiales por aumento de valor de las fincas, establece unos criterios diferenciales detallados para determinarlo (arts. 24 a 27, ambos inclusive) en base tanto a su localización, edificabilidad, etc., como a la tipología de la actuación municipal, constituyendo así una demostración, ciertamente inferior a las posibilidades actuales, de lo que puede lograrse para intentar la equidad en su aplicación. 
a las Corporaciones en desviación de poder si no imponen con tales bases las contribuciones especiales.

Similar criterio adopta para determinar los sujetos pasivos y fijar las cuotas individuales, no dudando, además, en reducir-prácticamente eliminar-la representación de los intereses colectivos de los contribuyentes en el procedimiento administrativo del tributo, ya que-probablemente con razón en muchos casos (28)-lo dificultaba.

Un breve repaso a la legislación aprobada después de la Ley de Régimen local (29) justificará los anteriores juicios de valor. La Ley Especial de Barcelona (D. 1166/1960)-que mantiene (art. 65) la misma participación del tributo que aquélla-admite que en los casos de aplicación de contribuciones especiales por beneficio especial se pueda sustituir el reparto analítico de las cuotas (art. 67) por un tanto alzado de tipo unitario. La utilización de tales módulos no sólo facilita la imposición del gravamen, sino que con ello el legislador permite una simplificación del procedimiento de aplicación, que minimiza decisoriamente las garantías del contribuyente establecidas en la Ley de Régimen local (art. 465) y Reglamento de Haciendas locales (cap. IV, sec. $2 .^{a}$ ), ya que, en tal caso, no se exige la constitución de la asociación administrativa de contribuyentes, verdadera salvaguardia de los derechos del sujeto pasivo, a la que concedía quizá una excesiva competencia el Reglamento -su artículo 27 indica que puede incluso oponerse a la realización de la obra-y, consecuentemente, es posible que entorpezca la actuación municipal (30), pero aun así difícilmente se justifica su eliminación.

En la Ley Especial de Madrid (D. 1674/1963) se da un nuevo

(28) Según GonZÁlez-Berenguer «las célebres contribuciones especiales sólo prosperan si los contribuyentes, por comprender la justicia del intento, por abulia o por lo que sea, no impugnan el establecimiento de este sistema impositivo. Porque lo cierto y verdad es que cuando lo impugnan sus probabilidades de éxito son abrumadoras. La experiencia que al respecto tienen los Ayuntamientos es grandemente negativa. Los pleitos sobre contribuciones especiales los pierde la Administración en un altísimo porcentaje» (GonzÁlez-BERENGUER, J. L.: Ob. cit., pág. 675).

(29) La Ley del Suelo de 1956 en su artículo 183-su texto se incluyó en la de 1975 (art. 198) y fue derogado por el Real Decreto 3250/1976 (Disposición final 2.8)establecía el límite de la imposición de contribuciones especiales en función de su coste para las obras ejecutadas por los Ayuntamientos.

(30) Parece lógico admitir que si los contribuyentes se oponen a una realización del Municipio que les reportaría unos beneficios individualizados-además de los generales-no inferiores al importe del tributo, ello sólo puede deberse a que su propia valoración no coincide con la de la Administración, o que no exista una demanda real para la obra o a que esperen trasladar el gravamen a otros, aunque esto último es más problemático dado el carácter obligatorio de la imposición de contribuciones especiales en la legislación vigente. 
e importante paso en tal dirección, pues establece el mismo criterio (art. 93), pero en ella alcanza un valor decisorio dado que su aplicación puede generalizarse a todas las contribuciones especiales que se impongan, al considerar el beneficio especial-los expertos consideran que el concepto engloba los aumentos de valorcomo la única causa para su imposición (art. 90). Además, dicha norma-por primera vez-exige con carácter obligatorio la imposición del tributo cuando el Ayuntamiento realice las obras especificadas en el artículo 469 de la Ley de Régimen local que, como se indicó, en ésta se consideraba era, en tales casos, potestativo del ente local su aplicación. Es decir, el legislador, de hecho, considera que siempre y en todo caso producirán beneficios especiales dichas obras, lo cual es ciertamente dudoso.

Un paso definitivo en el logro de los objetivos hacendísticos -y.en el desdibujamiento de los principios doctrinales del tributolo constituye la Ley 48/1966 y el Real Decreto 3250/1976 (31). En ambos se indica que las contribuciones especiales se impondrán en razón del beneficio individualizado (32) que reporten las obras (artículos 9,1 , y 23, respectivamente)-el gravamen, una vez más, se justifica así explícitamente por la capacidad contributiva que ello exterioriza-y establecen que su imposición será siempre obligatoria para los tipos de actuación que especifican con claridad (artículos $\left.9,2^{\circ}, a\right)$, y 26,1$)$, mientras que para otras tipologías, también definidas en ambas (arts. 9, $2 .^{\circ}$, a), y 26, 2), será potestativo del Ayuntamiento su aplicación. En el primer caso, el conjunto de beneficiarios debe satisfacer-con obligatoriedad-una parte del coste de la realización que origina la aplicación del gravamen, fijando tanto la indicada Ley (art. 9, $5^{\circ}$ ) como el Real Decreto (art. 29) sús porcentajes concretos-también con carácter coactivo-en función de la tipología de la actuación como único determinante, aunque

(31) La Ley de Régimen local establecía (art. 465) que la constitución de la Asociación Administrativa de Contribuyentes era forzosa-salvo limitadas excepciones-, y que una de sus misiones consistía en la inspección de la realización, la revisión de las cuentas y la comprobación de éstas (art. 26, 1, del Reglamento de Haciendas locales). En el Real Decreto 3250/1976 se contempla la posibilidad de su creación (artículo 35, 1) - sin carácter obligatorio-, pero establece tales condiciones en base al presupuesto de la obra, a la participación de contribuyentes y aun al tiempo concedido para solicitar su constitución (art. 33, 5), que, como indicó D'Ocon, se ha convertido en «una mera hipótesis, una entelequia» (D.'OcoN, J.: «Las relaciones 'Administración-contribuyente' en la Contribución Especial», Revista de Economía y Hacienda Local, enero-abril 1977, núm. 19, pág. 223).

(32) El Real Decreto 3250/1976 indica (art. 23, 2) expresamente que el aumento de valor de determinadas fincas como consecuencia de realizaciones municipales tiene, a efectos de aplicación de contribuciones especiales, la consideración de beneficio especial. 
en la primera se preveía que un texto posterior-nunca dictadoespecificase (art. 9, 5.,$e$ ) ) los casos y condiciones en que podrían o debieran reducirse, así como su cuantía, mientras ya se determinan las reducciones (art. 30) en el Real Decreto 3250/1976, aun cuando ello no contribuya a hacer más equitativa la aplicación del tributo.

Pues bien, la demanda ciudadana de una realización municipal y las externalidades que ocasiona dependen, entre otros condicionantes, de aspectos socio-económicos, urbanos y aun climáticos de la zona en que se efectúe. Por tanto, el fijar con carácter general que los beneficios especiales que reporta una específica obra son los mismos o similares en cualquier Municipio o aun en todas sus zonas, no resiste el análisis más superficial, y ello es lo que establecen, de hecho, tanto la Ley 48/1966, como el vigente Real Decreto 3250/ 1976. Además, al evaluar los beneficios especiales como un porcentaje determinado del gasto efectuado en la obra, los que se producirán en realidad no tienen, ni aun presuntamente, virtualidad al ser sustituida su cuantificación efectiva por el indicado índice, que constituye una mera presunción legal, a la que el legislador concede, además, un carácter obligatorio, que, por tanto, elimina por innecesario cualquier intento de valoración válida, y con ello toda la justificación doctrinal del tributo-que costeen parcialmente las obras aquellos que obtienen ventajas individualizadas en proporción a éstas-parece que ha sido marginada así en la normativa y, ciertamente, en la práctica.

Sin entrar en una detallada justificación de las anteriores afirmaciones, pues se volverá sobre ello más adelante, un par de consideraciones podrán dar idea aquí de la inadecuación de la normativa a las bases doctrinales del tributo. Por ejemplo, las valoraciones de los beneficios especiales establecidas en la legislación supone admitir, entre otras cosas, que si se aumenta el costo de una obra, se incrementan las ventajas individualizadas en la misma proporción (33), lo cual es indefendible. Otro ejemplo: según la normativa, producirán beneficios especiales a los mismos agentes la sus-

(33) El costo de una realización depende, en primer lugar, de la productividad y economicidad con que se utilicen los recursos, y, ciertamente, nadie asegurará que se logre optimizarlos siempre. Por otro lado, el gasto que ocasiona está influido por factores exógenos que lo condicionan; por ejemplo, la misma instalación de alumbrado público tendrá un coste inferior si existen galerías de servicios que si no se dispone de ellas, variación que puede superar el 25 por 100 del gasto global. Estas galerías de servicios en ningún caso serán costeadas, ni parcialmente, por los presuntos beneficiarios de la iluminación, de acuerdo con el Real Decreto 3250/1976 (artículo $27,2, d)$. 
titución de aceras (art. 29, 1, del Real Decreto 3250/1976)-tanto si se amplían como si se estrechan-, según la decisión que tome la Administración local, la cual, dado el carácter obligatorio de la aplicación del tributo, deberá imponerlo en ambos casos.

\section{CONSECUENCIAS DE LA NORMATIVA}

\section{El BENEFICIO ESPECIAL: UNA ENTELEQUiA}

Sin duda, la legislación vigente responde a la opinión de un gran número de expertos-quizá una mayoría-que estiman conveniente conseguir la máxima objetivación en la aplicación del tributo, a fin de alcanzar las expectativas que proporciona en orden a lograr con ello el reforzamiento y mejora de las haciendas locales. Este objetivo-al concederle carácter prioritario-les justifica, además, como ha ocurrido con el legislador, el eliminar la posible oposición de los contribuyentes a la imposición mediante la marginación de canales administrativos adecuados, y así lo expresan, sin ambigüedades, en sus publicaciones. Por ejemplo, Rovira indica (34) que si las contribuciones especiales se fundamentan «en la producción u obtención de un beneficio particular en razón de la obra pública, es necesario llevar esta tesis a sus últimas consecuencias: objetivar totalmente la imposición evitando el requisito de probar y estimar la existencia del beneficio», y considera que «no ha de ser difícil llegar por la vía legal y la reglamentaria (...) a un repertorio de hechos imponibles totalmente objetivados, que priven de discutir la existencia del beneficion.

Así, nadie parece preocuparse porque se impongan las contribuciones especiales sin ajustarse, con realismo (35), a los principios

(34) Rovira y Mola, A. de, y otros: Casos prácticos de las contribuciones especiales, Madrid, Instituto de Estudios de Administración Local, 1972, págs. 22 y 23.

(35) Se han dado otras razones justificativas para objetivar la aplicación del tributo, además de las administrativas y fiscales. Por ejemplo, VEGA, al referirse a la discrecionalidad que la Ley de Régimen local (art. 470, 2) concedía a la Corporación - cuyo objetivo, indica, era «lograr una garantía de justicia»-, estima que ello puede conducir a una desviación de poder al valorar «excesivamente el interés privado con la finalidad de imputar un mayor porcentaje del coste (de la obra) a los particulares afectados" (VEgA Herrero, M.: Ob. cit., pág. 159). Sin duda, ello es posible, pero, aun así, parece que entraña una mayor posibilidad de adecuar la imposición del gravamen a los principios tributarios de las contribuciones especiales que ajustándose a la normativa vigente por dos motivos fundamentales: en primer lugar, porque dada la incidencia de los factores exógenos a la propia realización--específicos del entorno en que se realice-sobre las externalidades que ocasione, sólo es válida una evaluación individualizada en cada caso de los beneficios especiales que proporcione, y, en 
tributarios que las justifican-en aras de objetivos administrativos y hacendísticos-, al aplicarlas con los criterios impositivos determinados en la normativa, pues no parerce que pueda admitirse, como se indicó anteriormente, que las bases imponibles establecidas en ellas definan con suficiente rigorismo los beneficios particularizados que proporcionan las específicas externalidades ocasionadas por la obra efectuada. Si a ello se le añade que la determinación por el legislador de los sujetos pasivos del gravamen-los que estima consiguen las ventajas individualizadas-tampoco es posible considerar que tenga siempre una validez compatible con los dictados de equidad y generalidad, no parece arriesgado afirmar que el gravamen aplicado según la normativa tiene poco que ver con el concepto de contribución especial. Tal como indica BARRIL (36)-aunque base su conclusión en otras premisas-, si lo que se desea es «la sencillez administrativa, la seguridad y el previo conocimiento de la cuota exacta por la Administración y administrados»-la mejora de las haciendas locales subyace entre sus motivaciones-, hay que buscar «un procedimiento que permita la transformación de las contribuciones especiales en una tarifa que se liquide como un derecho o tasa fiscal». Ciertamente ello eliminaría el eufemismo actual y permitiría alcanzar los objetivos reales del legislador, probablemente sin ocasionar los costos sociales que hoy se producen al imponer el tributo.

Pues, dada la normativa vigente, la aplicación de contribuciones especiales puede llevar unido, o quizá con más realismo, muchas veces supondrá la vulneración de los dictados de equidad e igualdad, con los consiguientes costos sociales que ello implica. Así, la legislación no asegura-ni aun con un criterio laxo-que se imponga el tributo, en la mayoría de las ocasiones, a aquellos que realmente obtienen las ventajas personalizadas que justificarian su contribución al coste de las obras $\mathrm{y}$, mucho menos, que se armonice su cuantía con la manifestación de su capacidad contributiva real. Por otro lado, parece evidente que el legislador no da un trato igual a todos los sujetos pasivos; así, por ejemplo, en Barcelona-según establece el Real Decreto 3250/1976 (disposición final 1. ${ }^{a}, 4$ ), conserva el régimen impositivo anterior a su promulgación-, de acuerdo

segundo lugar, por ser más fácil que el Ayuntamiento las valore-dada su proximidad al hecho y a los administrados-con mayor realismo que una norma que determina con carácter general, unívoco y obligatorio la base imponible y los sujetos pasivos.

(36) BARRIL DoSSET, R.: "El mito de la precisión en las contribuciones especiales», El Consultor de los Ayuntamientos, 10 de julio de 1970, núm. 22, págs. 1020 y 1023. 
con su Reglamento de Hacienda Municipal (art. 11), podrá aplicarse, en función del método administrativo seguido en el procedimiento de aplicación, lo dispuesto en la Ley del Suelo (art. 183) o en la de Régimen local (art. 470, b) ), que fijan de forma distinta la parte del costo de la obra que debe cubrir el tributo. Con ello, las contribuciones especiales que se impondrán serán muy distintas para obras iguales. Por ejemplo, para la construcción de una acera de seis metro de ancho es posible varíe el importe del gravamen en el 270 por 100, según se aplique de acuerdo con lo dispuesto en una u otra Ley.

\section{Minimiza las ventajas DEL tRibuto}

Complementariamente, la normativa vigente anula $\mathrm{o}$, por lo menos, minimiza muchos aspectos positivos que una aplicación adecuada del tributo proporcionaría. Entre ellos podrian citarse su contribución a la reducción de incertidumbres decisorias en los órganos de gobierno de la Corporación local, a la mejor asignación de los siempre escasos recursos municipales, a incrementar el interés por conseguir externalidades positivas, y como consecuencia de los estudios que su imposición exigiría, se facilitaría tanto el control interno y aun externo de la gestión-si se concediesen las garantías jurídicas adecuadas a los contribuyentes-, como su transparencia, objetivos estos últimos que son prioritarios para todos en el plano teórico, pero que en la práctica cotidiana son marginados, incluso por los propios ciudadanos; pues su interés real se centra en los aspectos finalistas de la actuación municipal que les afectan de forma directa y personal (37).

(37) Un ejemplo permitirá dar una idea de la poca importancia que el ciucladano concede a la gestión municipal mientras no le afecte directamente. En el Pleno del Ayuntamiento de Madrid de 27 de julio de 1977, un Concejal, Consejero de la Empresa Municipal de Transportes (EMT), propuso su privatización para evitar la subida de tarifas y que la Corporación absorbiese el déficit existente. En declaración posterior ( $Y a$, agosto 1977) dijo que «la gestión directa es mala», que «la municipalización ha fracasado en Madrid», que la absorción de los microbuses constituyo «una mala operación» y que «la gestión fue un fracaso». Los dias 2 y 3 de agosto la prensa se hace eco de un escrito de nueve empresas privadas de transportes en el que afirman que si se privatiza la EMT concurrirían con sus ofertas, sin que ni los partidos políticos, los sindicatos o las asociaciones vecinas concedan interés a todo ello. EI 10 de enero de 1978 la prensa madrileña recoge unas explicaciones del Alcalde y otros responsables de la EMT-déficit desde su creación, bancarrota económica, etc.-que obligan a subir las tarifas-se efectuó el 8 de enero de 1978-, y es por entonces cuando, por primera vez, un Diputado se refiere al tema al declarar a El Pais (6 de mayo de 1978) que el incremento era «injustificado e ilegal», y numerosos partidos 
Así, para imponer con validez contribuciones especiales por la realización de una obra municipal, sería necesario efectuar un análisis de su demanda y de los beneficios especiales que proporcionaría o de la eficacia lograda, cuando la falta de evaluación de éstos obliga a utilizar índices. Ello contribuiría a que la Corporación pudiese tomar sus decisiones con aceptable objetividad (38), facilitaría la elección de la opción más conveniente y permitiría establecer con realismo la prioridad que debiera conceder a una realización determinada, dentro del marco general de las prestaciones que ofrece y de los recursos disponibles. Lógicamente, esto no quiere decir que si se intentase imponer el tributo con arreglo a las bases doctrinales, se lograrían per se estos objetivos, sino que la necesidad de conseguir en tal caso una aceptable evaluación de las externalidades que ocasione una obra estimularía, tanto al político como al funcionario, a ser más analíticos y aun creativos y a procurar una constante mejora en sus cuantificaciones, objetivo alcanzable dado el carácter repetitivo de la actuación municipal que proporciona la posibilidad de comprobaciones expost, que sirven como plataforma para nuevas valoraciones iterativas. La normativa vigente, al establecer con carácter obligatorio las bases objetivadas de la imposición del tributo, no sólo no estimula la consecución de estos objetivos fundamentales, sino que los margina de la actividad municipal.

Por otro lado, la adecuada imposición de las contribuciones especiales facilitaría la consecución de una asignación eficiente de los recursos municipales, pues dado el carácter de cuasi-precio del tributo, incentivaría la demostración de las preferencias de los ciudadanos, y con ello se avanzaría en el logro de disponer de una información que, al orientar las resoluciones del órgano de gobierno del Ayuntamiento, reduciría incertidumbres decisorias por contribuir a revelar la demanda de las realizaciones municipales y evitaría una excesiva e indeseada preponderancia del experto (39), cuyas

políticos, sindicatos y asociaciones de vecinos convocan una manifestación para el 26 de enero-según afirman los diarios del 17-para protestar por la subida.

(38) Es importante resaltar que, como indicó ACKOFF, a veces, los que toman las decisiones sobre lo que se hará en el sector público "prestan (...) mayor importancia a aquellos objetivos por los que ellos están luchando en ese momento y descuidan los que ya han conseguido. Otros, más honrados, pero igualmente alejados de la realidad, confeccionan una refinada escala de valores y tratan de imponer a los demás su propia concepción del bienestar" (SECCI, B., y otros: Análisis de las estructuras territoriales, Barcelona, Ed. G. Gili, S. A., 1968, pág. 409).

(39) Hasta ahora, el peso del proyectista de la obra ha sido excesivo en una gran parte de las Corporaciones locales, pues ha tomado, de hecho, la decisión quizá más importante: establecer la calidad de la prestación y las características de la realización, prácticamente, sin ninguna intervención ni control de los órganos políticos o de la Administración general del ente, con evidente dejación de las responsabilidades de 
decisiones-fundamentalmente la adopción del estándar de las prestaciones (40)-sustituyen hoy, de forma generalmente subjetiva y con muy reducida o aun nula responsabilidad y control, estos conocimientos relevantes, marginando así, además, la soberanía de los ciudadanos y la posibilidad de satisfacer sus necesidades al enmascarar la realidad, que debe ser la que guíe los criterios políticos. Mientras que la normativa actual, al fijar con carácter obligatorio la parte del costo de la obra que debe cubrir el tributo y concederle un carácter general, no reconoce la variedad de preferencias locales, no contribuye al establecimiento de los estándares demandados por los ciudadanos-sean válidos o no siempre tendrán la misma respuesta tributaria-y no estimulará la mejora en el conocimiento de los requerimientos de la población.

Por último, las contribuciones especiales se basan, como se ha indicado, en que la actuación del Ayuntamiento, que se costea parcialmente con ellas, debe ocasionar externalidades que benefician a las funciones de utilidad o producción de diversos agentes particularizados, beneficios que al estar relacionados directamente con el importe del tributo- «se establecen para reintegrar a la comunidad parte del beneficio que, derivado de la actuación municipal,

éstos. Ante esta realidad-aún hoy usual en la mayoría de los Ayuntamientos-cada vez son más contundentes las críticas a este proceder, totalmente lógicas desde cualquier punto de vista. Como un ejemplo de los muchos que podían citarse de estas opiniones se puede recordar-por su carácter general-lo que indicó DE TERÁN al referirse al papel más amplio que puede desempeñar un proyectista: el de planeador. Debe abdicar, dijo, "del brillante papel de forjador del futuro, que había asumido indebidamente, para aceptar su lógico puesto de asesor experto de la comunidad, devolviendo a ésta las elecciones fundamentales» (DE TERÁN, F.: Planeamiento Urbano en la España Contemporánea, Barcelona, Ed. G. Gili, S. A., 1978, pág. 628).

(40) Campos Venuti, para definir las formas y contenidos urbanos, establece dos conceptos: las funciones urbanísticas- «las exigencias a satisfacer por el hombre cuan. do construye las ciudades»-y los estándares, que son sus «expresiones cuantitativas» (Campos Venuti, G.: La Administración del Urbanismo, Barcelona, Ed. G. Gili, Sociedad Anónima, 1971, pág. 112). Por consiguiente, la adopción de un estándar constituye una decisión básica de la Administración local, pues es condicionante de la calidad de vida urbana y su determinación racional exige conocer la demanda-si la oferta la supera habrá despilfarro, y si no la satisface, se ocasionarán costos sociales y deseconomías-, así como su previsible incidencia sobre los agentes socio-económicos y los recursos que exigirá. Bajo el aspecto administrativo constituye, además, un instrumento imprescindible para planificar y redactar programas de actuación, racionalizar las decisiones presupuestarias, conseguir el control necesario de la gestión, etcétera. Por ello, la adopción del estándar debe ser una decisión del organo de gobierno del ente que no es admisible sea reemplazado en ello por el experto-frecuen. temente en base a decisiones proyectuales-, pues el cometido de éste es informar, bajo el punto de vista de sus conocimientos profesionales, las opciones existentes y de sus ventajas e inconvenientes, y, una vez tomada la resolución política, debe conseguirla maximizando la economicidad. 
se alcanza a bienes, a personas o a clases determinadas» (41)constituyen, en potencia, un estímulo para que la Administración local incremente su interés por maximizarlos, como consecuencia de obvios motivos hacendísticos, sociales y de imagen. De esta forma son, aplicados con criterios armónicos a sus bases conceptuales, un incentivo y un válido instrumento para buscar la optimización de la eficacia social de los recursos públicos utilizados en las realizaciones que se financian con el citado tributo. Lamentablemente, al objetivar mediante una normativa de aplicación obligatoria-como ocurre ahora en España-la imposición de contribuciones especiales, parece plausible admitir que se elimina el estímulo para la búsqueda de externalidades positivas (42), pues la legislación vigente permite actuar al ente local, en la práctica, como si siempre que efectúa alguna de las obras tipificadas por el legislador obtuviese beneficios especiales, incluso de similar cuantía, y de hecho margina su responsabilidad por una aplicación inadecuada, bajo el punto de vista del equilibrio ventajas-gravamen, siempre que se ajuste a lo legislado, al quedar asumida por la norma.

\section{Paradótica incidencia financiera}

A lo largo de los apartados anteriores se ha indicado repetidamente que el legislador, en las normas de aplicación de las contribuciones especiales dictadas desde que se instauraron en España, parece que busca, como objetivo fundamental, el potenciàr las haciendas locales, introduciendo en las sucesivas regulaciones aprobadas nuevos aspectos de la exacción tendentes a eliminar o reducir las causas que, en su momento, parecían impedir la consecución de las expectativas económicas que proporciona el tributo-todos los tratadistas están de acuerdo en que no se alcanzaron en ningún momento-, al cual muchos consideran, como indicó VEGA, «la

(41) Gaja Molins, E.: Ordenación de las contribuciones especiales, Madrid, Instituto de Estudios de Administración Local, 1974, pág. 23.

(42) Según Krueckeberg y Silvers «un administrador (...) no asigna valor a las externidades que pudieran generar sus programas: no se le recompensa por generar externalidades positivas ni nadie parece requerirle indemnizar a terceros por los costos provocados por externalidades negativas», y continúan: «quienes son responsables de decidir (...) tienen poco incentivo para tomar debidamente en cuenta las externalidades» (Krueckeberg y Silvers: Análisis de Planificación Urbana, México, Ed. Linusa, 1978, pág. 263). 
fuente más idónea para proveer de los recursos financieros pertinentes a las Corporaciones locales» (43).

La opinión sobre el objetivo del legislador de potenciar los aspectos fiscales de las contribuciones especiales se basa en una serie de reformas introducidas en la normativa-varias de ellas ciertamente afortunadas-, entre las que pueden recordarse: el carácter obligatorio de la imposición del tributo (art. 26, 1, del Real Decreto $3250 / 1976$ ) cuando el ente efectúe muchas de las realizaciones especificadas en el artículo 469 de la Ley de Régimen local-y otras más-que en ésta eran potestativas; la sustitución de los límites máximos del importe global del gravamen (art. 470) de la citada Ley por unos coeficientes fijos que determina la norma (art. 29, 1, del Real Decreto 3250/1976); la constitución (44) de la Asociación Administrativa de contribuyentes, que era obligatoria-en la mayoría de los casos-, según lo dispuesto en la Ley de Régimen local (artículo 465), y que no sólo perdió este carácter en el Real Decreto $3250 / 1976$ (art. 35, 1), sino que prácticamente la marginó; las subvenciones $u$ otras cooperaciones que, según la Ley de Régimen local, debían descontarse del coste de las obras (art. 454, 3), deben incluirse ahora en él (art. 28, 5, del Real Decreto 3250/1976); la simplificación del régimen jurídico del tributo-LlaMAS consideró al inicial "endiablado» (45)-, etc.

Ciertamente, no todas las disposiciones de la norma-Real Decreto $3250 / 1976$ sobre contribuciones especiales-contribuyen a potenciar su aspecto fiscal, entre las que parece interesante resaltar aquí dos. Una de indudable carácter restrictivo: la derogación del tributo dentro del marco de la Ley del Suelo (disposición final 1. ${ }^{a}$, $\left.5,2 .^{a}\right)$, y la otra, que ciertamente implica un juicio de valor: la previsible complejidad que introduce en su aplicación las reducciones de los porcentajes de participación del gravamen en el costo total de las obras-además de disminuir su importe-, establecidas en su artículo 30.

Por la Ley del Suelo ha estado vigente desde 1956 hasta 1979

(43) Vega Herrero, M.: Ob. cit., pág. 65.

(44) Los expertos en el tributo consideran que la Asociación se utiliza con frecuencia para crear «una oposición clara, tenaz y temeraria a los propósitos municipales» (GAJA Molins, E.: Ob. cit., pág. 254), sin que parezca que ninguno considere que ello pueda estar justificado, lo cual es probable, pues, racionalmente, si los bene. ficios logrados fuesen inferiores a la base imponible y existiese una demanda real para la obra, carecería de lógica esta postura, sobre todo con carácter mayoritario, si no surge el problema del free rider, es decir, el intento de trasladar el gravamen a otros, lo cual no parece fácil y podría conllevar que no se efectuase la prestación deseada, con el consiguiente perjuicio para los que la demandan.

(45) Llamas labella, M. A.: Ob. cit., pág. 30. 
-artículos 183 de la Ley de 12 de mayo de 1956 y 199 del Real Decreto 1349/1976-la imposición de contribuciones especiales para la financiación de la ordenación urbanística cuando incurrían determinados requisitos concretos, entre ellos, que correspondiesen a obras de primera urbanización, pues debían incluirrse en el presupuesto especial de urbanismo, en el que sólo pueden figurar éstas, según determinan los artículos 196 y 192 de las citadas disposiciones. Su derogación es un tanto paradójica en el contexto actual, pues quizá sean éstas las obras que permiten una mejor cuantificación de las ventajas particularizadas y es más fácil determinar los sujetos que las obtienen, aunque a ello podría haber contribuido la «tendencia progresiva de financiar las obras de urbanización a través de la iniciativa privada y aun de la gestión pública mediante figuras compendiadas en los llamados cánones de urbanización, que pueden motivar una disminución del campo de aplicación de aquellas contribuciones especiales», como se recogía (46) en una conclusión del IV Seminario de Investigación del Instituto de Estudios de Administración Local.

Para dar una idea de la importancia que ello podrá tener sobre las haciendas municipales, se puede indicar que las contribuciones especiales que figuraban en los presupuestos de urbanismo que se preveían imponer en los años 1970-1974, aunque no todas ellas se aplicasen según lo dispuesto en la Ley del Suelo, representaban sobre el total de las incluidas en los presupuestos ordinarios, especiales y extraordinarios municipales porcentajes (47) que oscilan entre el 27 por 100 (1973) y el 35 por 100 (1971).

Por su parte, la reducción de los porcentajes de participación del gravamen en el coste de las obras especificadas en el artículo 30 del Real Decreto 3250/1976 no sólo disminuye su importancia hacendística, sino que en muchos casos es previsible que incremente la complejidad de su imposición, cree incertidumbres impositivas, por su ambigüedad se preste a estimular la oposición de los sujetos pasivos, etc., sin que, además, pueda admitirse que, con carácter general, contribuya a racionalizar la aplicación del tributo y adecuarlo a sus principios tributarios.

Por ejemplo, en relación con las obras de alumbrado público -indudablemente las que resultan (48) más conflictivas para apli-

(46) Seminarios de Investigación 1970. Conclusiones, Madrid, Instituto de Administración Local, 1972, pág. 79.

(47) Fuente: Anuario Estadístico de las Corporaciones Locales.

(48) La parte del costo de las obras de alumbrado público que debe financiarse con contribuciones especiales será, según el Real Decreto 3250/1976, del 70 por 100 
car lo dispuesto en el citado artículo 30-, las reducciones que deben efectuarse se basan fundamentalmente en «la intensidad lumínica normal» de las restantes vías públicas del Municipio, pues sí se excede ésta, se disminuirá en un 50 por 100 el porcentaje de participación del tributo en el costo de la realización sobre los fijados con carácter general (art. 29, 1, b) y c)).

La norma no define, ni aun aclara, a qué denomina el legislador intensidad lumínica normal, que por su posible importancia tributaria constituye un concepto básico para la actuación municipal en el sector. Pues bien, en general, en una población se establece el nivel técnico de la iluminación-la intensidad lumínica es casi siempre uno de sus parámetros-en función del objetivo visual que se desea satisfacer en cada caso-básicamente necesidades del peatón o conductor -o urbanístico: creación de un ambiente agradable, armonizar la importancia urbana de la vía y el alumbrado de que se la dote, etc., y, por tanto, se adoptan distintas intensidades lumínicas (49) en función de las características de las vías o de su clasificación.

Como consecuencia de ello, parece racional que la intensidad lumínica normal que debe considerarse (50) en cada caso, para adecuar el importe de las contribuciones especiales a lo dispuesto en el artículo 30 del Real Decreto 3250/1976, sea la que corresponda a la tipología de la vía en la cual se realice. Esto exige, para satisfacer los cánones de certidumbre, la previa determinación de las diversas intensidades lumínicas normales y las vías a que corres-

cuando se trate de establecimiento y sustitución, mientras sólo alcanzará el 50 por 100 si corresponde a una mejora (art. $29,1, b$ y $c$, respectivamente). Esta ambigua redacción impide al responsable de la aplicación del tributo conocer el criterio establecido por el legislador, pues toda mejora-salvo la ocasionada temporalmente por una operación de mantenimiento, por ejemplo, limpieza de luminarias-exige una sustitución, parcial o total, de la instalación y normalmente, por no decir siempre, una sustitución de parte o todos los componentes lleva unida una mejora.

(49) Unos ejemplos de los niveles luminosos que se adoptan en nuestras poblaciones nos lo dan las Ordenanzas sobre el uso del suelo y edificación del Ayuntamiento de Madrid (art. 51, 11), que fija tres valores mínimos en función de la tipología de la vía, o el de Barcelona, que en su Ordenanza número 20 (Anexo $1, d, 1$ ) establece ocho bandas para la iluminación que se alcanzará en las distintas calles y plazas.

(50) Podrían darse otras interpretaciones al concepto, pero no parecen tan racionales. Por ejemplo, sería posible considerar como intensidad lumínica normal la mínima que se alcance en la población, que normalmente se lograra en calles de fondo de saco localizadas en zonas residenciales, en base a considerar que fuera la única que produce beneficios especiales a los vecinos de la vía. Esta hipótesis es poco defendible, pues no permitiría alcanzar los objetivos mínimos que la iluminación debe satisfacer en las demás calles y supondría la eliminación fáctica de los porcentajes establecidos como base (art. 29, 1, b y c) en el Real Decreto 3250/1976 para determinar la parte de la obra que debe financiarse con contribuciones especiales. 
ponde cada una de ellas. Si esto se hace así, carece de racionalidad y aun de la lógica más elemental que el alumbrado público realizado en una vía supere el nivel cuantitativo que el ente local, con total discrecionalidad, ha establecido previamente, por lo cual el precepto parece innecesario; pero dada su incidencia sobre la cuantía del tributo, es lógico que los sujetos pasivos deseen medir la intensidad lumínica alcanzada a fin de procurar reducir su contribución. Ello crea una nueva incertidumbre, pues la sistemática de la medición-no definida en el Decreto-puede incidir en los resultados (51) constituyendo así una fuente de problemas.

Desgraciadamente, dado que no se publica desde 1976 el Anuario Estadístico de las Corporaciones Locales, no es posible conocer la importancia tributaria (52) de las contribuciones especiales a partir de la aprobación del Real Decreto 3250/1976, que concede carácter obligatorio a su imposición para un gran número de obras (artículo 26,1 --responsabiliza solidariamente a los miembros de la Corporación, así como a los Secretarios e Interventores si no se aplican (artículo 34)-, y con anterioridad, todos los tratadistas están de acuerdo en que la Administración local ha procurado soslayar su imposición, incluso mediante el incumplimiento de los requisitos legales, como parece ha puesto de manifiesto la jurisprudencia en muchos casos.

No obstante, en la tabla que se incluye a continuación, se facilitan algunos datos sobre lo que han supuesto las contribuciones especiales en los Ayuntamientos de régimen común durante los últimos años sobre los que existe información estadística.

(51) La intensidad lumínica de un alumbrado se reduce como consecuencia de la suciedad que se acumula sobre los sistemas ópticos de las luminarias, for el envejecimiento de los mismos, por la depreciación del flujo luminoso que emiten las lámparas a lo largo de su utilización y por la caída de tensión del suministro de la energía. En la mayoría de nuestras poblaciones, dado el deficiente mantenimiento de las instalaciones, dicha intensidad varía en más del 50 por $100 \mathrm{y}$, en el mejor de los casos, oscilará cerca del 30 por 100 . Ello da una idea válida de cómo incidirá en los resultados de la medición el momento en que se haga ésta, a lo que hay que añadir que también influye en ello la propia sistemática adoptada para medir, aunque ciertamente con mucho menor peso.

(52) Es posible que desde las elecciones municipales de 1979, dado que en una gran parte de los Ayuntamientos tienen mayoría los partidos socialista y comunista, la imposición de contribuciones especiales tienda a reducirse, ya que ninguno de ellos es partidario de potenciarlas, según ha indicado el autor J. Valles FERRER, Director Federal del Centro de Estudios de la Administración del PSOE, mientras un Comité del partido comunista afirmó: «el criterio es tratar de reducir progresivamente su alcance» (Gabinete Técnico Municipal del Comité Provincial De MadRid Del Partido Comunista de España: Cambiar Madrid, Madrid, Ed. Ayuso, 1979, pág. 380). 
CONTRIBUCIONES ESPECIALES

\begin{tabular}{|c|c|c|c|c|c|c|c|}
\hline \multirow{4}{*}{ Años } & \multicolumn{7}{|c|}{ I $\quad M \quad P \quad O \quad R \quad T \quad E$} \\
\hline & \multirow{3}{*}{$\begin{array}{l}\text { Miles de ptas. } \\
\text { (corrientes) }\end{array}$} & \multirow{3}{*}{$\begin{array}{l}\text { Indices en ptas. } \\
\text { constantes }(\star)\end{array}$} & \multirow{3}{*}{$\begin{array}{l}\% \text { sobre } \\
\text { ingresos }\end{array}$} & \multicolumn{4}{|c|}{ PORCENTAJES EN LOS DISTINTOS PRESUPUESTOS MUNICIPALES } \\
\hline & & & & \multirow{2}{*}{ Ordinarios } & \multicolumn{2}{|c|}{ Especiales } & \multirow{2}{*}{ Extraordinarios $(* \star)$} \\
\hline & & & & & Urbanismo & Otros & \\
\hline $\begin{array}{l}1965 \\
1966 \\
1967 \\
1968 \\
1969 \\
1970 \\
1971 \\
1972 \\
1973 \\
1974\end{array}$ & $\begin{array}{l}1.514 .298 \\
1.682 .177 \\
2.324 .162 \\
3.000 .845 \\
3.211 .353 \\
3.488 .646 \\
4.339 .532 \\
5.656 .064 \\
6.127 .393 \\
5.610 .802\end{array}$ & $\begin{array}{r}52 \\
55 \\
71 \\
87 \\
91 \\
93 \\
108 \\
130 \\
126 \\
100\end{array}$ & $\begin{array}{l}5,61 \\
4,82 \\
5,68 \\
6,51 \\
5,76 \\
5,59 \\
5,94 \\
6,48 \\
6,15 \\
5,01\end{array}$ & $\begin{array}{l}21,00 \\
19,29 \\
18,26 \\
14,74 \\
16,22 \\
19,25 \\
15,97 \\
13,17 \\
17,81 \\
13,07\end{array}$ & $\begin{array}{l}36,75 \\
37,75 \\
31,30 \\
25,18 \\
40,79 \\
32,88 \\
35,04 \\
29,04 \\
27,06 \\
32,61\end{array}$ & $\begin{array}{l}0,05 \\
0,03 \\
0,04 \\
0,18 \\
0,23 \\
0,00 \\
0,12 \\
0,01 \\
0,01 \\
0,01\end{array}$ & $\begin{array}{l}42,20 \\
44,93 \\
50,39 \\
59,90 \\
42,76 \\
47,87 \\
48,87 \\
57,78 \\
61,11 \\
54,31\end{array}$ \\
\hline
\end{tabular}

(*) Pesetas deflactadas por el índice de coste de la vida.

(a) Desde ex punto de vistraordinarios con los demás, ya que su vigencia es definida; pero, a efectos estadísticos, ello puede ser orientativo de la importancia del tributo.

Fuentes: Anuario Estadistico de las Corporaciones Locales y Anuario Estadistico de España. 


\section{ASPECTOS SECTORIALES}

\section{INVALIDEZ DE LA GENERALIZACIÓN IMPOSITIVA}

Anteriormente se han hecho ya algunas consideraciones que resaltan la inadecuación de las bases imponibles que la normativa vigente determina para cuantificar los beneficios personalizados, pero su falta de validez se maximiza al conceder a las mismas un carácter general-con matizaciones de dudoso realismo-que impide tener en cuenta las muy diversas características de una demanda condicionada por aspectos socio-económicos, urbanos e incluso climáticos. Así, una misma externalidad puede ser considerada por los afectados como positiva o negativa según su localización; el distinto uso del suelo, que influye en la jerarquización de las necesidades para los diversos sujetos, es posible que varíe decisoriamente los beneficiarios individuales; una tipología de personas o clases que obtienen ventajas privatizadas en unos casos, es indudable que en otros se perjudican, y algo similar ocurre como consecuencia de la incidencia de variables culturales, económicas, etc. Tres ejemplos es posible confirmen estas afirmaciones.

A) «En climas con días calurosos y noches cálidas, el alumbrado puede aumentar el volumen de uso comunal (de una zona), especialmente por adolescentes y adultos, en comunidades donde 'sentarse fuera' es una tradición cultural» (53). Por tanto, la implantación de una iluminación que cree condiciones visuales adecuadas a la deseada actividad social proporcionará normalmente unos beneficios indudables a los vecinos; pero la misma instalación-gravada, por tanto, con iguales contribuciones especiales y que, por consiguiente, producirá similares ventajas según la legislaciónpuede proporcionar beneficios marginales nulos en relación con otra de menor calidad que, por ello, permita una reducción cuantitativa del tributo en zonas climáticas frías y lluviosas o donde la calle es una mera vía de tránsito, así como en comunidades que conceden valor primordial a la privacidad-como ocurre, en general, con las de mayor renta per capita-, y, por tanto, la calle sólo en casos específicos es lugar de asentamiento para ellos.

(53) CAnter, D.; LEe, T., y otros: Psichology and built environment, Londres, Architectural Press Ltd., 1974, pág. 129. 
B) La accesibilidad es una condición básica para la vida de los conjuntos comerciales por dos razones fundamentales. En primer lugar, porque crean un tráfico atraído que es muy superior al que generan y atraen las viviendas $u$ otros usos del suelo (54) por unidad de superficie bruta edificada; en segundo lugar, porque su poder de atracción sobre los clientes potenciales viene determinado, entre otros factores, por la "relación inversa a la distancia» (55)—su incidencia se expresa normalmente en el tiempo empleado para recorrerla en automóvil-«entre dicho elemento y la residencia de los compradores», como indicó Voor HeEs (56). Por tanto, a partir de cierto nivel, las empresas comerciales del área interiorizan las deseconomías de congestión, y de ahí que obtengan beneficios individualizados más importantes los titulares del dominio útil de inmuebles destinados a actividades comerciales, que los de edificios utilizados para otros fines-a efectos de aplicación de contribuciones especiales, la normativa los considera iguales-, cuando el ente local realiza acciones para mejorar la accesibilidad de la zona.

C) De acuerdo con lo dispuesto en la Ley de Arrendamientos Urbanos (art. 108), el arrendador de una vivienda o local puede exigir del arrendatario el abono de un porcentaje anual del importe de las contribuciones especiales sufragadas por aquél, que el Real Decreto-ley 21/1979 fija en un 12 por 100 (art. 1, 2). Esta disposición, que, en general, supone una obligatoriedad para el arrendatario es, a veces, totalmente inadmisible, pues puede corresponder a realizaciones-como ocurre con frecuencia al abrir una calle $u$ otra actuación-que posiblemente incrementan el valor de la propiedad, por ejemplo, al facilitar el cambio de uso, pero no ocasionan ventajas similares al inquilino o arrendatario. Ello afecta con más frecuencia a los grupos más pobres, cuyas opciones económicas son limitadas, tienen jerarquizadas sus necesidades con claridad y pocas veces desean emplear sus-ingresos en mejoras urbanas que, dado su

(54) En el estudio de la demanda de transporte en el centro comercial de Azca de Madrid se establecieron, entre otros, los siguientes índices de producción de viajes/ día de persona por $10 \mathrm{~m}^{2}$ de superficie bruta edificada: 1,5 para viviendas, 14,27 para oficinas semipúblicas y 37,14 para el gran comercio (VALDÉs GonzÁlez-RoLDÁN, A., y otros: Ingeniería de Tráfico, Madrid, Ed. Dossat, 1971, pág. 493).

(55): El efecto del factor distancia tiene una mayor incidencia en los viajes de compras que en desplazamientos realizados por otras motivaciones. Por ejemplo, este

factor es $\sqrt{\mathrm{D}}$ para viajes debidos al trabajo, y para los ocasionados por la compra oscila entre $\mathrm{D}^{2}$ y $\mathrm{D}^{3}$, según el tipo de ésta (Cecarelli, P., y otros: Las incógnitas det tráfico urbano, Barcelona, Ed. G. Gili, S. A., 1971, pág. 79).

(56) Cecarelli, P., y otros: Ob. cit., pág. 75. 
nivel de vida, consideran secundarias e incluso pueden perjudicarles al contribuir al cambio de las características del barrio (57).

Otros muchos ejemplos podrían ponerse, dado que la demanda de prestaciones públicas está, como se indicó, condicionada por muy diversos factores, entre ellos, la morfología urbana, el nivel de motorización, la renta per capita, etc., que impiden considerar que la realización de una obra municipal cree externalidades que proporcionen unos beneficios especiales de importancia similar en todas las ocasiones. De ahí que sea lógico esperar que un tal criterio no satisfaga, en la mayoría de los casos, los principios de justicia tributaria y que la imposición de contribuciones especiales en su contexto ocasione-si existen cauces para ello-la oposición de amplios sectores de contribuyentes.

Existen dos factores principales para que el sujeto pasivo no recurra jurídicamente contra la imposición del tributo, aun cuando la realización municipal que lo ocasione no le proporcione beneficios especiales y, por tanto, falte su causa legitimadora. En primer lugar-y es la razón básica-, porque los afectados por el procedimiento administrativo de aplicación del tributo no pueden impugnarlo por dicha causa, dado que la normativa ha objetivizado sujetos pasivos, bases imponibles y módulos de reparto. Esto elimina la posibilidad de que pueda ser controvertida por tal motivo, mientras coadyuva a ello lo dispuesto en la legislación sobre la Asociación Administrativa de contribuyentes, que (58) «en la práctica ha desaparecido" (59). El otro factor limitativo de las impugnaciones

(57) Según se indica en una publicación de la OCDE, realizar mejoras en un barrio-incluso las poco costosas y aun efectuadas a expensas del erario de la Corporación local, por lo que sus afirmaciones se maximizan en el caso de aplicar contribuciones especiales-pueden perjudicar a los vecinos de rentas bajas por dos razones: en primer lugar, porque la mejora "puede hacer subir a tal punto el costo de la vivienda en el barrio que los residentes iniciales, que no tienen ninguna participación en el capital inmobiliario, pueden ser forzados a abandonarlo para irse a otro más pobre y menos costoso, cediendo el sitio en el barrio mejorado a residentes más afortunados». La otra razón es consecuencia de que si una realización no tiene demanda real por parte de los vecinos puede dar más satisfacción al promotor «que a los habitantes a los que era destinada inicialmente la mejora» (GROUPE DE L'OCDE SUR L'Environnement Urbain: Mieux vivre en ville, París, Organisation de Coopération et de Developement Economiques, París, 1978, pág. 40).

(58) D’Ocon, J.: Ob. cit., pág. 222.

(59) El Grupo de la OCDE sobre Ambiente Urbano indicó que «los habitantes conocen los defectos de su entorno y debieran tener algo que decir en las decisiones referentes a la manera de remediarlos. Los métodos de trabajo de las autoridades locales debieran ser adaptados de manera que hiciesen posible una tal participación del público» (GROuPE DE L'OCDE sUR L'ENVIRONNEMENT URBAIN: Ob. cit., pág. 10). Parece admisible que la Asociación administrativa de contribuyentes pudiera ser un cauce para conseguir esta colaboración. 
es debido a que la gente, como ocurre cuando se ocasiona una deteriorización ambiental u otro tipo de agresión-algo que sucede muchas veces con las realizaciones que la normativa de las contribuciones especiales estima que siempre ocasionan ventajas individualizadas (60)_, como mucho protesta inicialmente, pero con posterioridad se resigna con rapidez ante el hecho, aunque si se examinan las reacciones individuales, en general, se manifiesta la queja durante mucho tiempo.

\section{IRREAL CUANTIFICACIÓN DE LOS BENEFICIOS}

Ciertamente, no sólo es difícil admitir que puedan cuantificarse los beneficios especiales que reporta una obra municipal con criterio generalista-y ello parece ser la hipótesis justificativa de lo. establecido en el Real Decreto 3250/1976, en relación con la parte del costo de la realización que debe financiarse con contribuciones. especiales-, sino que incluso alguna de las bases en que se funda su actual imposición, por ejemplo, que la aplicación del tributo sea independiente de la utilización por los interesados de la obra (artículo 24 del Real Decreto 3250/1976), es poco defendible, pues no cabe duda que si bien algunos agentes ocasionan demanda de opciones (61), otros no, y, por tanto, difícilmente se justifica conceptualmente que contribuyan económicamente a su realización en este caso. Además, este criterio puede ser aceptable para unos agentes, pero no para otros, como ocurre en algunas circunstancias con lo establecido en el artículo 14, 2, del Reglamento de Hacienda Municipal de Barcelona, que indica procede la imposición del tributo, aunque la finca disfrute por alguna de sus fachadas, o partes, de

(60) Lawson y Walters, de la Escuela de Arquitectura y de la Universidad de Aston, ambas de Birminghan, estudiaron el impacto de una autopista sobre una zona. residencial-degradación visual, separación, ruido, vibración, polución atmosférica, etcétera-y sobre sus habitantes. El vecindario, según sus conclusiones, reaccionó inicialmente-durante unas semanas-de forma "bulliciosa y agitada con una sensación de atropello", pero después de un año, "por lo menos en la superficie», se habían calmado (CANTER, D.; LEE, T., y otros: Ob. cit., pág. 137).

(61) No cabe duda que algunos agentes ocasionan demanda de opciones. Así, ROPOPORT cita un ejemplo de ello: «aunque solamente un 7-16 por 100 de los usuarios de un nuevo barrio deseaban usar las zonas de esparcimientos y sus servicios, un 90 por 100 piden que estos servicios y esta zonas existan por causa del simbolismo de status que otorgan" (RoPOPOR,, A.: Aspectos humanos de la forma humana, Barcelona, Ed. G. Gili, S. A., 1978, pág. 65). Lógicamente la demanda de opciones es, en general, decreciente con la disminución de la renta. 
instalaciones análogas a las que se trate de ejecutar (62). Así, por ejemplo, si el inmueble ya evacua sus aguas residuales es posible que un nuevo alcantarillado en calle limítrofe pueda beneficiar al propietario por mejorar las expectativas económicas (63) del solar, pero difícilmente ello ocasionará ventajas particularizadas a los inquilinos del edificio.

Más importancia que lo indicado tiene el hecho de que es posible afirmar, sin excesivo riesgo, que el legislador no ha cuantificado con bases realistas los beneficios especiales que ocasionan determinadas obras, sino que parece ha adoptado para ello criterios erráticos dadas las variaciones que se observan en las sucesivas disposiciones legales. Parodiando a JARDIEL Poncela, es posible indicar que el criterio adoptado parece ser la falta de criterio.

Por ejemplo, la imposición de contribuciones especiales por primer establecimiento o renovación de aceras era potestativa del ente, según la Ley de Régimen local (art. $469, e$ ) ) y la Ley del Suelo (art. 198), y obligatoria por la Ley $48 / 1966$ (art. 9, 2, a) ) y el vigente Real Decreto 3250/1976 (art. 26, b) ). Según las distintas normas, el importe global del tributo debía alcanzar los siguientes porcentajes del costo total de la obra:

a) 100 por 100 si la acera no superase los dos metros de ancho, y si tuviese más, el coste proporcional a esa anchura (Ley de Régimen local, art. 470, b) ).

b) Con cualquier anchura no sobrepasaría el 90 por 100 (Ley del Suelo de 1975, art. 198, y de 1956, art. 183).

c) 100 por 100 hasta una anchura de dos metros, y si la supera, al resto se le aplicaría el 90 por 100 en primeras instalaciones, y el 50 por 100 cuando sean renovaciones (Ley 48/1966, art. 9, d) ).

(62) Como indica Fornesa, si una instalación existente alcanza «a satisfacer plenamente las necesidades de un contribuyente $\mathrm{y}$, por tanto, éste no puede obtener beneficio alguno como consecuencia de las obras o instalaciones que se realicen en otra calle, con la que asimismo linde la finca de su propiedad, será preciso admitir que no se ha producido, en su caso concreto e individual, el presupuesto de hecho necesario para el efectivo devengo de las contribuciones especiales» (FoRNESA RiBo, R.: "Las fincas que lindan con varias calles y su problemática en el ámbito de las exac. ciones locales», Revista de Economia y Hacienda Local, mayo-agosto 1971, núm. 2, página 256).

(63) Aun cuando el propietario de un inmueble pueda mejorar sus expectativas, por la realización de una obra en una calle limítrofe a su propiedad, los beneficios especiales que obtendrá, si ya disfruta la finca por alguna de sus fachadas de instalación similar, serán inferiores a los obtenidos por otros contribuyentes que no están en su caso. Ello, aun cuando la normativa no lo ha tenido en cuenta, sí lo pondera la Ordenanza Fiscal número 20 del Ayuntamiento de Barcelona (art. 8, 2, 3 y 4). 
d) 90 por 100 hasta una anchura de dos metros en las obras de primer establecimiento, y 50 por 100 si son de sustitución. Si la anchura se mantiene entre dos y seis metros, el porcentaje a aplicar entre ambas será de 45 por 100 a 25 por 100 , según fuese la obra de primera instalación o reposición. A las anchuras superiores a seis metros no se aplicarán contribuciones especiales (Real Decreto 3250/1976, arts. 29, 1, y 30, 3. $)$.

Pero esto no es todo, ya que relacionar la anchura de la acera con los beneficios especiales que reporte normalmente carece de sentido, pues las ventajas que proporciona están más influidas por otros condicionantes, como puede ser el uso del suelo, que por la anchura. Por ejemplo, en una zona comercial, la dotación de aceras amplias es condición básica para su desarrollo-como indicó FouRNIER (64), Director general de «Carrefour»-, y así «el fácil acceso de peatones y su integración en rutas peatonales existentes fueron consideradas cuestiones de primera importancia en encuestas efectuadas entre comerciantes» (65), mientras que en zonas residenciales, en calles sin actividad comercial, las aceras sólo constituyen un espacio de paso-sobre todo en barrios de clases medias o altas-, aun cuando sean amplias, estén bien pavimentadas e incluso hermoseadas, como comprobó JACoBS (66). Por ello, en zonas comerciales puede carecer de realismo el variar la cuantía de las contribuciones especiales al superar la acera anchuras de dos metros, incluso de seis metros, y ser válido el hacerlo en calles residenciales.

Algo similar podría indicarse de otras tipologías de actuaciones incluidas en la normativa, mientras parece posible afirmar que el criterio inconsistente del legislador se extiende asimismo a las realizaciones municipales que considera ocasionan ventajas particularizadas, dado que en las sucesivas normas dictadas varía las obras que estima las producen. Así, haciendo referencia exclusiva a aquellas que la legislación considera que siempre que se realicen deben imponerse obligatoriamente contribuciones especiales, se puede indicar que en la Ley del Municipio de Madrid (art. 90, 2) se

(64) Dirección General de Comercio InTERior: Los futuros centros comerciales en España y su situación actual en el extranjero, Madrid, Ministerio de Comercio, 1972, pág. 49.

(65) National Economic Development OfFice: The future pattern of shopping, Londres, H. M. S. O., 1971, pág. 36.

(66) Proshansky, H. M., y otros: Psicología ambiental, México, Ed. Trillas, 1978, página 415. 
incluyen en ellas, por ejemplo, la plantación de arbolado o la cons. trucción de ferrocarriles o tranvías (67), que no figuran con tal carácter ni en la Ley 48/1966 ni en el Real Decreto 3250/1976, mientras que, en este último, se establece que la aplicación del tributo es obligatoria en actuaciones que, en las otras disposiciones, no figuran ni aun como potestativas del ente local: instalaciones de redes de distribución de energía eléctrica (68) o el primer establecimiento-e incluso sustitución-de bocas de riego (69).

Por otro lado, los Reales Decretos 688/1978 y 1779/1978 sobre Planes Provinciales de Obras y Servicios, parece que inciden negativamente sobre los principios básicos de las contribuciones especiales, ya que para las obras que determina el primero (art. 7, a) ) -incluye un menor número de tipologías que el Real Decreto 3250/ 1976 (art. 26, 1)-reduce el porcentaje del coste que debe cubrir el tributo, pues lo limita al 10 por 100 (art. 7, b)) en Municipios de población inferior a 10.000 habitantes o al 25 por 100 en los demás Ayuntamientos. Por su parte, el Real Decreto 1779/1978 establece (artículo 4) que, en el contexto de los Planes Provinciales, las Corpo-

(67) Sorprende que el Real Decreto $3250 / 1976$ no incluya entre las obras que deben financiarse parcialmente mediante contribuciones especiales, con carácter obligatorio, las relacionadas con el transporte público aun cuando «es evidente la estrecha correlación que existe entre el valor del suelo y su accesibilidad; la implantación de los sistemas de transporte (público) produce, por tanto, una revalorización de las zonas a las que afecta». Lógicamente ello parece que justificaría la implantación del tributo en estos casos, pues «estas plusvalías deberían ser las que pagasen todo o parte de los costos de construcción" (Valero Calvete, J.: Transportes urbanos, Madrid, Ed. Dossat, S. A., 1970, pág. 283). Complementariamente debe resaltarse que el Grupo de Trabajo de la OCDE sobre los indicadores del ambiente urbano-que describen la calidad del entorno-incluye entre ellos «el porcentaje de la población que tiene acceso a una parada de los transportes públicos urbanos en un radio de $x$ metros» (Groupe de Travail SUR les Indicateurs D'ENVIRONNEMENT: Indicateurs d'environnement urbain, París, Organisation de Coopération et de Developement Economique, 1978 , pág. 40).

(68) En la normativa derogada, el porcentaje del costo de las realizaciones de alumbrado público que se podría financiar con contribuciones especiales era el 80 por 100 en la Ley de Régimen local (art. 470, 1), el 90 por 100 en la Ley del Suelo de 1956 y 1976 (arts. 183 y 198, respectivamente), así como en la 48/1966 (artículo $\left.9,5^{\circ}\right)$, en la que ya se establecía la obligatoriedad de imponer el tributo. Como en el Real Decreto $3250 / 1976$ se fija este porcentaje (art. 29, 1) entre el 70 por 100 -establecimiento y sustitución de alumbrado público-y el 50 por 100-mejora del mismo-y, además, se incluye la instalación de redes de distribución de energía eléctrica entre las obras que deben financiarse con dicho gravamen-el 90 por 100 del costo-, se comprende que varios autores hayan asimilado estas últimas obras a las de la iluminación pública (BoRja, I., y otros: Manual de formación municipal, Barcelona, Centre d'Estudis Urbanistics Municipals i Territorials, 1979, pág. 179; MarTín SAMPEDRo, J. M.: «Las contribuciones especiales en las nuevas normas provisionales», Revista de Economía y Hacienda Local, mayo-agosto 1977, núm. 20, pág. 114; etc.).

(69) Es difícil admitir que la implantación de bocas de riego (art. 26, 1, b, del Real Decreto 3250/1976) ocasione beneficios especiales, pues, previsiblemente, benefician a la comunidad al contribuir a reducir el costo de los servicios municipales que las utilizan, costo que es sufragado por todos los vecinos. 
raciones locales podrán aplicar el gravamen entre los porcentajes indicados en el Real Decreto 688/1978 y los fijados en el artículo 29 del Real Decreto 3250/1976. Es decir, que parece se vulnera así el principio de generalidad, ya que para obras similares, que producirán, por tanto-según el criterio establecido en la normativa-, los mismos beneficios especiales, los contribuyentes serán gravados con importes muy distintos, según se les aplique el tributo en el marco del Real Decreto 688/1978, del Real Decreto 1779/1978 o en el del Real Decreto 3250/1976.

Por último, tampoco en la definición de los sujetos pasivos se ha seguido en la normativa un criterio congruente. Así, por ejemplo, la Ley de Régimen local (art. 468, b) ) establecía que en la rectificación de rasantes estaban particularmente «comprendidas en la obligación de contribuir (...) las empresas que ejerzan habitualmente el transporte en las vías mejoradas», sin que en la legislación posterior se haga mención a ello. Mayor importancia tiene que en el Real Decreto 3250/1976 no se incluya ninguna referencia a la imposición de contribuciones especiales a los poseedores del bien (70), pues en muchas ocasiones serán los principales beneficiarios, mientras ello ya se especificaba-con ambigüedad-en el artículo $16 \mathrm{del}$ Reglamento de Haciendas locales.

Además, aun cuando una gran parte de las obras urbanas, por no decir todas, irradian su influencia a una zona más extensa que la colindante a la realización-algunas de ellas, como las que afectan al alcantarillado o a las redes de distribución de aguas y energía eléctrica, es incluso fácil determinar la extensión de su incidencia zonal en cada caso concreto (71) dada su morfología-, la normativa, unas veces, no lo ha tenido en cuenta de forma expresa para la imposición de contribuciones especiales, mientras que, en otras, al determinar los sujetos pasivos de manera hipotética y general,

(70) Martín SAMPEDro, al resaltar esta omisión, indica que «parece que ello ha debido quedar, en ánimo de los redactores de las normas, para desarrollar en el reglamento" (MarTín SAMPEdro, J. M.: Ob. cit., pág. 117).

(71) Cuando se realiza una red de distribución, tanto de aguas como de energía eléctrica, cada tramo se dimensiona en función de la demanda de la zona que se suministra o suministrará por su medio. Es decir, que la obra de una gran parte de los tramos creará beneficios zonales y su costo dependerá no sólo de las necesidades de las fincas de su entorno, sino de factores exógenos a ellas: demanda de la zona a la que afecta, tipología de las redes, etc. Por tanto, la imposición de contribuciones especiales, de acuerdo con sus principios conceptuales, debería efectuarse en base de los beneficios zonales que ocasionará la realización que, en el caso de instalaciones eléctricas, no son considerados en el Real Decreto 3250/1976, y para las correspondientes al suministro de aguas, el criterio de «aplicar índices correctores en razón inversa a la distancia», como se indica en su artículo $31, d$, carece de toda validez. Algo similar ocurre con el alcantarillado. 
determinación que impone jurídicamente, no se ajusta a criterios válidos, creando así una nueva e importante incertidumbre sobre la validez conceptual de su aplicación.

Así, por ejemplo, en la Ley de Régimen local no se hacía ninguna indicación expresa a los posibles beneficios zonales que ocasiona una obra, aunque esto no fue decisorio, dado que el criterio establecido en ella para fijar las cuotas individuales (art. 471) del tributo era lo suficientemente amplio para que pudiera imponerse a sujetos pasivos localizados fuera de las inmediaciones de la realización; pero alcanza una importancia trascendente, entre otras normas, en el Real Decreto 3250/1976, pues su articulado sólo especifica que ocasionarán intereses zonales las obras de captación, embalse, depósito, conducción y depuración de aguas para el abastecimiento, así como las estaciones depuradoras de aguas residuales y colectores generales (art. 31, d)). Ello no es defendible, pues es obvio que, además de éstas, otras muchas pueden aportar beneficios zonales. Por ejemplo, las rentas de situación-uno de los condicionantes del precio del suelo-se derivan, entre otros factores, de su accesibilidad. De ahí que las obras que la afecten: apertura y ensanchamiento de calles, instalación de alumbrados públicos, etcétera, causarán beneficios individuales que no se limitan a las fincas inmediatas, sino a todas la de la zona en que con ellas se mejore su acceso a los polos de atracción de la población.

\section{Otros ASPECTOS DISCUtibLES}

Podrían citarse aspectos de la normativa que difícilmente pueden considerarse adecuados, pero se hará aquí referencia a sólo tres de ellos que, con los anteriores, quizá sean los más importantes y trascendentes: la aplicación de contribuciones especiales por obras de modificación, renovación o sustitución; la marginación en la norma de las externalidades negativas que muchas veces ocasionarán y la reducción de los porcentajes de participación del tributo en el costo de la realización establecidos en el Real Decreto 3250/ 1976 (art. 30).

Como se indicó, la generalización de la aplicación de contribuciones especiales por obras de primer establecimiento no puede considerarse aceptable, pero es mucho más inadecuado que se establezcan índices exclusivamente jurídicos-fijados con carácter ge- 
neral-para evaluar los beneficios individuales que proporcionará una obra que mejore, renueve, etc., realizaciones ya existentes (72).

Dos son las razones principales que avalan estos juicios de valor. La primera es consecuencia de que si ya existe una posible gran dispersión en los beneficios especiales reales que ocasiona una misma externalidad, como consecuencia de estar condicionados por una serie de aspectos que pueden variar enormemente de un caso a otro, ello se maximiza cuando se efectúa una mejora o se realiza una actuación similar, pues su variabilidad aún será mayor, ya que, además de los condicionantes anteriores, existe otro de decisiva incidencia: las ventajas individualizadas que proporciona la prestación de la que se parte, pues, como es lógico, serán distintas en cada ocasión. Por tanto, si no parece posible admitir unos índices generales para cuantificar los beneficios privatizados que crea una obra de primer establecimiento, ello aún es más inadecuado en el caso de una mejora, reemplazamiento, reforma, etc. La otra razón es que el costo de este tipo de realizaciones tiene poca relación con las ventajas individualizadas que proporcionan, incluso menor que en actuaciones correspondientes a implantaciones de nuevo establecimiento $\mathrm{y}$, por consiguiente, conceder carácter general al porcentaje del gasto que debe financiarse con contribuciones especiales es muy difícil que pueda aceptarse si no se admite la marginación, quizá fuese más exacto decir la eliminación, de los "principios de generalidad y equitativa distribución de la carga tributaria", que la Ley General Tributaria considera básicas en la imposición de los tributos (art. 3).

Ello es obvio porque a las razones indicadas para obras de primera implantación hay que añadir otro factor de variabilidad que, en mejorás, renovaciones, etc., tiene siempre una incidencia importante y muy dispersa sobre su costo: las características de la prestación existente. Un ejemplo será suficiente para resaltarlo: un alumbrado público que proporcione un determinado nivel de iluminación, según sean las características geométricas de la instalación, así como las de las luminarias y red eléctrica existente, puede mejorarse, por ejemplo, duplicándolo mediante la sola sustitución de las lámparas y balastros unas veces, mientras que otras exigirá el reemplazamiento total de la realización actual. Por ello puede

(72) La obligatoriedad de aplicar contribuciones especiales a determinadas obras de mejora, renovación, sustitución, etc., se estableció por primera vez en la normativa por la Ley del Municipio de Madrid (1963) y, posteriormente, se extendió a los demás Ayuntamientos mediante el artículo 9 de la Ley 48/1966 y, si se considera que éste no lleg6 a estar en vigor, por el Real Decreto 3250/1976 (art. 26, 1). 
indicarse, con carácter orientativo, que los costos de iguales mejoras pueden oscilar en ambos casos en más del 1.000 por $100-\mathrm{y}$, consiguientemente, el importe de las contribuciones especiales-, aun cuando es evidente que a igualdad de las demás condicionantes, los beneficios que reportan son iguales.

Todo lo indicado cobra una especial trascendencia si se considera, como parece previsible, que el importe de las contribuciones especiales que se impongan por este tipo de realizaciones tendrá cada vez un mayor peso sobre su volumen global por dos razones fundamentales: en primer lugar, por no aplicarse el tributo en el contexto de la Ley del Suelo, y en segundo, porque la mayoría de las poblaciones ya tienen, en su mayor parte, las dotaciones que pueden financiarse por contribuciones especiales, pero en una gran proporción, de una calidad inferior no sólo a lo que podría considerarse aceptable, sino a los mínimos admisibles, y, por tanto, no parece arriesgado prever que se concederá a su mejora un interés creciente. Otra razón coadyuvante será la obligatoriedad de imposición de las contribuciones especiales para la ejecución de este tipo de obras a partir de la aprobación del Real Decreto 3250/1976, pues con anterioridad, dadas las distintas opiniones sobre la vigencia del artículo $99^{\circ}$ de la Ley 48/1966, sólo tenía ese carácter en Madrid (art. 90, 2, del Decreto 1674/1953).

Por otro lado, en unos momentos en que existe un gran interés por identificar las causas de las externalidades negativas que se producen en las poblaciones y se intenta reducir su impacto; cuando la opinión pública se opone en todo el mundo a las prioridades urbanísticas de hace sólo unos años, pues valora con más rigor las disfunciones a que daban lugar (73); en unas circunstancias en que se procura interiorizar los efectos negativos externos que ocasionan los distintos agentes ciudadanos, etc., y se sabe que la mayoría de las acciones urbanas producen externalidades negativas (74), por

(73) Reissman, y podrían citarse opiniones similares de una gran mayoría de expertos, indicó: «a menudo (...) la solución adoptada empeora los problemas de otras áreas, e incluso hay veces que, a largo plazo, se empeora el problema concreto que había que resolver» (ReIssman, L.: El proceso urbano, Barcelona, Ed. G. Gili, S. A., 1970 , pág. 34).

(74) Casi todas las realizaciones de los entes locales producen externalidades negativas más o menos importantes, e incluso alguna de ellas puede afectar decisoriamente a los beneficios especiales. Por ejemplo, DeRYCKE indica cómo una mejora en la red de transportes puede traducirse en «una disminución de los valores del suelo y de las densidades residenciales y por una extensión de los límites espaciales de la ciudad» (DERYCKE, P. H.: La economía urbana, Madrid, Instituto de Estudios de Administración Local, 1971, pág. 130), es decir, que una obra que mejore la accesibilidad puede perjudicar a los propietarios de las fincas situadas en sus inmediaciones y favo. recer a otros situados lejos de ella. 
lo que antes de tomar una decisión, aun la más simple, es necesario estudiar sus beneficios netos, es decir, ponderar las ventajas e inconvenientes que ocasionará, la normativa sobre contribuciones especiales ignora-no considera-que las obras a las que se apliquen puedan tener consecuencias indeseables para ciertos sectores.

Esta afirmación se basa en que la legislación no contempla la posibilidad de establecer una contribución especial negativa para indemnizar a aquellos afectados desfavorablemente, de forma individualizada, por la actuación del ente local-ello parece que está implícito en el concepto del tributo-, ni hace la mínima concesión o referencia a que las externalidades negativas (75) pueden incidir sobre los mismos que se benefician especialmente $y$, por tanto, verán reducidas las ventajas que obtendrían si no se produjesen. Además, en ningún caso incluye en el costo de realización-en función del cual se determina la base imponible-los posibles gastos que deben realizarse (76) para reducir o, como sería deseable, eliminar las desventajas-económicas o sociales-que se impondrán a otros y compensar, en su caso, las disfunciones que se les causen. Todo ello supone introducir un nuevo condicionamiento, que modifica la relación que podría existir entre beneficios especiales y costos de la

(75) Muy distintos ejemplos pueden ponerse de obras cuya realización conlleva simultáneamente externalidades positivas y negativas, muchas de las cuales afectan al mismo tiempo a agentes individualizados. Casos típicos son algunas mejoras en la calle, para cuya financiación deben imponerse contribuciones especiales con carácter obligatorio, según establece su normativa. Así, la mejora de una vía crea, normalmente, un tráfico atraído como consecuencia de la atracción que supone para el tránsito; un tráfico inducido, resultado de la mejora ocasionada, y un tráfico generado, debido a la variación experimentada por la infraestructura, cuyo volumen y composición dependerán decisoriamente de la localización, características de la urbe, etc. De esta forma, la mejora en la accesibilidad ocasionada por la obra ambiental (OrGANIZA'CIÓN DE COOPERACIÓN Y DesarRollo Económico: Efectos del tráfico y de las carreteras sobre el medio ambiente en áreas urbanas, Madrid, Ministerio de Asuntos Exteriores de España, 1975) tanto por factores de tráfico-ruido, polución atmosférica, vibraciones-como de la vía-intrusión visual y estética, separación psicológica y física, etcétera-que, en algunos casos, aconsejará la reducción de su impacto negativo mediante la adopción de medidas que pueden implicar costos, como, por ejemplo, concesión de ayudas financieras para compensar los gastos ocasionados por la utilización de dobles ventanas para reducir el ruido en el interior de los edificios. Lógicamente, en cada caso, las externalidades condicionarán con muy distinta incidencia los beneficios especiales.

(76) Con frecuencia, una realización que beneficia especialmente a alguien puede transferir costos a otros; por tanto, debía tenerse en cuenta al aplicar las contribuciones especiales con equidad. Por ejemplo, si mediante una sustitución de aceras se transforma una calle en peatonal, normalmente se beneficia el comercio-existen datos publicados sobre ello; por ejemplo (GrouPE DE L'OCDE SUR L'ENVIRONNEMENT URBAIN: Ob. cit., pág. 84), las ventas aumentaron en los de la calle Londres de Norwich un 25 por 100 al efectuar este tipo de obra-, pero puede perjudicar a otras actividades: un almacén de materiales pesados o a los vecinos de vías inmediatas que deben soportar el tráfico que circulaba antes por aquélla. 
actuación, creando complementariamente otra causa de variabilidad en las ventajas individualizadas que ocasiona la obra que se financia parcialmente con contribuciones especiales, y, por tanto, es un nuevo factor coadyuvante para considerar inaceptables las cuantificaciones que establece la normativa del tributo y su aplicación general (77).

Por último, las reducciones en los porcentajes del costo de las obras que deben financiarse mediante contribuciones especiales establecidas en el Real Decreto 3250/1976 (art. 30), y que afectan prácticamente a casi todas las actuaciones del ente local a las que se debe aplicar con carácter obligatorio (art. 26,1) el tributo, no parece que aporten mayor equidad a su aplicación por dos razones: en primer lugar, porque es difícil que tengan validez los índices de partida por todo lo indicado hasta aquí $y$, por tanto, es muy problemático que, a partir de ellos, puedan evaluarse con realismo y carácter general los beneficios personalizados que ocasiona una realización municipal, y en segundo lugar, porque las matizaciones. establecidas parecen, en muchos casos, poco válidas.

No es necesario insistir nuevamente sobre el primer motivo, mientras que algunas indicaciones sobre la última afirmación pueden justificarla. Así, por ejemplo, en relación con el alumbrado público, se establecen (art. 30, 3) en el Real Decreto 3250/1976 unas. reducciones sobre los porcentajes de participación de las contribuciones especiales fijadas con carácter general (art. 29, 1), que parecen incongruentes con otros dictados de su texto (78), pero llegan a ser absurdos, sin duda, cuando en la norma se fija como uno de los motivos para reducir en un 50 por 100 el importe del tributo,

(77) En las conclusiones de la Conferencia de la OCDE sobre «Calidad de la vida urbana y la limitación de la circulación», celebrada en abril de 1975 en París, se indica paladinamente: "la limitación de la circulación mejora la vida urbana», afirmación que sólo unos años antes sería inconcebible y ello no es más que un ejemplo del cambio fundamental que han experimentado las prioridades ciudadanas. Pues, como indicó CHuECA, hoy parece que la «verdadera solución no consiste en abrir vías para absorber el tráfico, sino en buscar los medios para que este tráfico disminuya. No en resolver el tráfico, sino en evitarlo" (CHuEcA Goitia, F.: La destrucción del legado urbanístico español, Madrid, Espasa-Calpe, S. A., 1977, pág. 42).

(78) En el Real Decreto 3250/1976 se establecen unas reducciones (art. 30, 2) sobre los porcentajes del costo de las obras de pavimentación (art. 29,1) que deben financiarse con contribuciones especiales en función del tipo de edificación y el ancho. de la calle, que incluso llegan a ser del 100 por 100 a partir de ciertos límites. Ello. supone que el legislador considera que si se sobrepasan éstos, la realización no proporcionará beneficios especiales, mientras que no fija similar reducción para las instalaciones que iluminan dicha parte de las calzadas, lo cual, evidentemente, es poco o nada congruente. 
la posición que ocupen los puntos de luz (79) o cuando hace posible que tengan que contribuir menos aquellos a los que se les proporciona una iluminación mejor (80). Aunque no todas las reducciones establecidas en el Real Decreto son tan manifiestamente inadecuadas, no es arriesgado afirmar que son en su totalidad discutibles, por lo que es posible afirmar sin riesgo que no introducen racionalidad ni equidad a la imposición del tributo.

\section{COMENTARIOS FINALES}

Dado que es imposible determinar, con carácter general, las externalidades que crea una obra municipal, ya que están condicionadas por factores socio-económicos, urbanos e incluso climáticos de la zona en que se realiza, no puede considerarse admisible que una específica realización ocasione, en todo caso, similares beneficios especiales. Por ello, la normativa vigente de las contribuciones especiales, en la que se objetiva de una manera unívoca y general la base imponible del tributo como una función exclusiva de la tipología de la obra que se realiza, no asegura que exista una relación

(79) Lógicamente, un alumbrado público viene definido por su nivel técnico-iluminancia, luminancia, uniformidad de ambas, control del deslumbramiento, etc.-, y si dos instalaciones proporcionan la misma iluminación, en la gran mayoría de los casos la situación de los puntos de luz no influye sobre la calidad de la prestación. Pues bien, el Real Decreto 3250/1976 prevé una reducción de los porcentajes generales establecidos para las contribuciones especiales del 50 por 100 (art. 30, 3) cuando aquéllos se sitúen en el eje de la calzada, es decir, los beneficios especiales que dos iluminaciones de igual calidad proporcionen variarán, según el legislador, en un 200 por 100 según la situación de los puntos de luz. En la realidad, la variación será aún mayor, pues una instalación con éstos situados en el centro de la calzada será sensiblemente más económica-para iluminaciones del mismo nivel técnico-que si se sitúan en ambas aceras, llegando a obtenerse un ahorro de hasta el 40 por 100 en eI primer caso.

(80) En el artículo $30,3 .^{\circ}, 1$, del Real Decreto $3250 / 1976$ se indica que si el alumbrado que se instale excede en su intensidad lumínica de la que sea normal en las restantes vías públicas del Municipio, el porcentaje de participación de las contribuciones especiales se reducirá en el 50 por 100 del establecido con carácter general. Pues bien, es posible que el costo de las instalaciones varíe menos del 10 por 100 $y$, sin embargo, una proporcione doble intensidad lumínica que la otra. Por ello, al aplicar la reducción del 50 por 100 al porcentaje general, en el caso de que se superase la intensidad lumínica normal, el gravamen podría ser menor para aquellos a los que se les proporcionaría más iluminación. Es interesante resaltar que la "Ordenanza Orientadora de Contribuciones Especiales», redactada por el IEAL y el Servicio Nacional de Inspección y Asesoramiento de las Corporaciones Locales, mejora decisoriamente esta parte del texto del Real Decreto 3250/1976 al indicar (art. 11, 3, 1. $)$ que la reducción del 50 por 100 se aplicará «a aquellas partes del costo imputable al exceso"s. 
adecuada entre el importe del gravamen y las ventajas individualizadas que realmente proporciona. Si a ello se une que tampoco sea aceptable el definir de forma general, como hace el legislador, los agentes que obtienen los beneficios especiales-por similares razones-, la aplicación del tributo dentro del marco establecido por la norma puede ocasionar unos costes sociales inadmisibles-es posible que contribuyan los que no consigan ventajas particularizadas mientras que no lo hagan los que realmente las obtienen-y, además, no estimula, incluso dificulta, una óptima asignación de recursos, ya que margina la búsqueda de externalidades positivas y la determinación de la demanda de la obra.

Indudablemente, una tal normativa ofrece atractivos para el funcionario responsable de la aplicación del tributo, y con carácter más dudoso, a la Corporación municipal. Así, la norma evita que el funcionario tenga que buscar la creación de externalidades positivas, definir las ventajas personalizadas que ocasiona la obra y determinar los agentes que las obtienen; además, elimina tanto su responsabilidad, como las consecuencias administrativas que una imposición inadecuada le acarrearía: con la norma vigente ambas se limitan a la mera satisfacción de su sistemática. Por otro lado, la vigente relación jurídico-tributaria es más conflictiva para la Corporación, pues si bien la imposición del tributo, de acuerdo con la norma, minimiza su responsabilidad cuando es obligatoria la exigencia de aplicar contribuciones especiales y facilita el logro de las expectativas económicas que éstas proporcionan-incrementa así la posibilidad de realizar obras durante su mandato-, la imposición del gravamen con carácter obligatorio y base preestablecida puede inducir, en casos de manifiesta injusticia, de incapacidad de pago del contribuyente, etc., a desviaciones de poder-que indudablemente se producen hoy-, a posponer la realización deseada o a adoptar similares soluciones heterodoxas.

Por todo lo indicado, una normativa de aplicación de contribuciones especiales más adecuada que la vigente al concepto doctrinal del tributo, al no objetivar con rigidez y generalidad el hecho imponible, exigiría una mayor autonomía de los Ayuntamientos que la actual y una capacidad de gestión del gravamen que muy pocos tienen hoy. No cabe duda que ambas son difíciles de lograr, pues, por un lado-como indicó Tomás-Ramón FERNÁNDEZ-, «la autonomía de los entes locales carece de una garantía constitucional precisa o, dicho de otro modo, se trata de una garantía abstracta que 
no asegura el quantum de esa autonomía» (81), y, además, «es lógico preguntarse sobre la utilidad que puede reportar a los pequeños Municipios el declararles autónomos, si dicha autonomía no pueden hacerla efectiva por sus escasos medios» (82), mientras que la potenciación de su capacidad para imponer el tributo con bases realistas es posible que pasase, para una gran parte de las Corporaciones locales, por la disponibilidad de una asesoría técnico-económica que les orientase, en cada caso, sobre los beneficios especiales que podría generar una específica obra y así pudiesen tomar sus decisiones con una incertidumbre aceptable.

(81) FERNÁNDEZ, Tomás-Ramón: «El sistema de distribución de competencias entre el Estado y las Comunidades Autónomas», RevisTa DE Estudios DE LA VIDA LOCAL, enero-mayo 1979, núm. 201, pág. 35.

(82) SÁnchez Díaz, J. L.: «Competencia y Autonomía Municipal», Revista DE Estudios DE LA VIDA LoCAL, enero-marzo 1980, núm. 205, pág. 92. 
REVL-1981, núm. 211. CASAL LOPEZ-VALEIRAS, J. M.. ASPECTOS POLEMICOS DE LAS CONT... REVL-1981, núm. 211. CASAL LOPEZ-VALEIRAS, J. M.. ASPECTOS POLEMICOS DE LAS CONT... 
REVL-1981, núm. 211. CASAL LOPEZ-VALEIRAS, J. M.. ASPECTOS POLEMICOS DE LAS CONT...

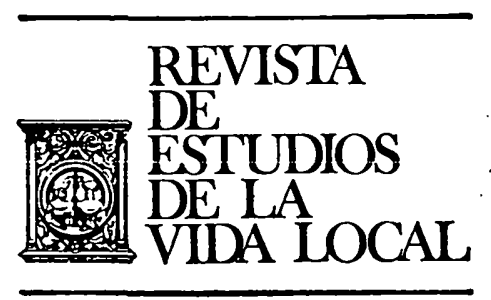

\section{CRONICAS}


REVL-1981, núm. 211. CASAL LOPEZ-VALEIRAS, J. M.. ASPECTOS POLEMICOS DE LAS CONT...

REVL-1981, núm. 211. CASAL LOPEZ-VALEIRAS, J. M.. ASPECTOS POLEMICOS DE LAS CONT... 